Systematic Review

\title{
E Improving Analgesic Efficacy and Safety of Thoracic Paravertebral Block for Breast Surgery: A Mixed-Effects Meta-Analysis
}

\footnotetext{
Abdullah S. Terkawi, MD ${ }^{1-3}$, Siny Tsang, PhD ${ }^{4}$, Daniel I. Sessler, MD, PhD ${ }^{3,5}$, Rayan S. Terkawi, MD², Megan S. Nunemaker, MSLS ${ }^{6}$, Marcel E. Durieux, MD, PhD', and Ashley Shilling, MD ${ }^{1}$

From: ${ }^{1}$ Department of Anesthesiology, University of Virginia, Charlottesville, VA; 2Department of Anesthesiology, King Fahad medical city, Riyadh, Saudi Arabia; 3 Outcomes Research Consortium, Cleveland Clinic, Cleveland, $\mathrm{OH}$;

${ }^{4}$ Department of Epidemiology, Columbia University, New

York, NY; 5 Department of

Outcome Research, Cleveland

Clinic, Cleveland, $\mathrm{OH} ;{ }^{6} \mathrm{Claude}$

Moore Health Sciences

Library, University of Virginia, Charlottesville, VA

Address Correspondence: Abdullah S. Terkawi, MD Department of Anesthesiology 1215 Lee St Charlottesville, VA 22908 E-mail: asterkawi@gmail.com. I

Disclaimer: There was no external funding in the preparation of this manuscript.

Conflict of interest: Each author certifies that he or she, or a member of his or her immediate family, has no commercial association (i.e., consultancies, stock ownership, equity interest, patent/licensing arrangements, etc.) that might pose a conflict of interest in connection with the submitted manuscript.

Manuscript received: 12-31-2014 Revised manuscript received: 04-02-2014 Accepted for publication: 05-12-2015

Free full manuscript: www.painphysicianjournal.com

Background: While most trials of thoracic paravertebral nerve blocks (TPVB) for breast surgery show benefit, their effect on postoperative pain intensity, opioid consumption, and prevention of chronic postsurgical pain varies substantially across studies. Variability may result from use of different drugs and techniques.

Objectives: To examine the use of TPVB in breast surgery, and to determine which method(s) provide optimal efficacy and safety.

Study Design: Mixed-Effects Meta-Analysis.

Methods: We conducted a systematic review of randomized trials comparing TPVB to no intervention using random-effects models. To evaluate the contributions of various techniques, clinical approaches were included as moderators in mixed-effects models.

Results: A total of 24 randomized controlled trials (RCTs) with 1,822 patients were included. Use of TPVB decreased postoperative pain scores at rest and movement at the first 2, 24, 48, and 72 hours. TPVB modestly decreased intraoperative and postoperative opioid consumption, reduced nausea and vomiting, and shortened hospitalization, but to a probably clinically irrelevant degree. Blocks also appeared to reduce the incidence of chronic postsurgical pain at 6 months. Adding fentanyl to the TPVB improved pain at rest (at 24, 48, and 72 hours) and movement (at 24 and 72 hours). Multilevel blocks provided better postoperative pain control, but only during movement (at 2,48 , and 72 hours). Fewer procedural complications (especially hypotension, epidural spread, and Horner's syndrome) occurred when anatomical landmarks were supplemented with ultrasound guidance.

Limitations: The number of studies available was limited in the meta-analytic model of incidence of chronic post-surgical pain.

Conclusion: TPVB reduces postoperative pain and opioid consumption, and has a limited beneficial effect on the quality of recovery. From all the techniques that were evaluated, only the addition of fentanyl, and performing multilevel blocks were associated with improved acute analgesia. TPVB may reduce chronic postsurgical pain at 6 months.

Key words: Thoracic paravertebral block, breast surgery, anesthesia, acute pain, chronic pain, nausea, vomiting, length of stay, techniques, variability, meta-regression, meta-analysis, moderators

Pain Physician 2015; 18:E757-E780
}

D reast cancer is the most common noncutaneous D cancer in U.S. women. In 2015, an estimated 60,290 cases of in situ disease and 231,840 new cases of invasive breast cancer were expected in the United States (1). Because breast surgery is the primary treatment modality for breast cancer, nearly all patients presumably had surgery (2).

A large European multicenter survey of postoper- 
ative pain management showed that current management remains suboptimal (3), which is consistent with a recent analysis showing little progress from 1993 to 2012 (4). In fact, about $40 \%$ of women still complain of clinically meaningful acute pain (i.e., $>5 / 10$ on a numeric rating scale) after breast cancer surgery (5). Failure to provide good postoperative pain control is associated with poor recovery, prolonged hospitalization, and possibly increased risk of developing chronic post-surgical pain (CPSP) (5). Numerous analgesic modalities have been suggested, including opioids, thoracic paravertebral blocks (TPVB), epidural analgesia, and lidocaine infusion (6), with variable efficacy and safety.

TPVB may be an effective analgesic approach for breast cancer surgery. Two meta-analyses $(7,8)$ showed TPVB to be a feasible and effective method for reducing pain after breast surgery. Most included studies showed TPVBs to provide effective analgesia, reduce opioid consumption, and decrease the risk of developing chronic postsurgical pain. However, treatment effect varied considerably among studies. Moreover, a recent well-designed randomized controlled trial (RCT) showed no significant improvement in acute or chronic pain of TPVB versus control (9).

Our purpose therefore was to: 1 ) examine the extent to which the use of TPVB reduces postoperative pain, decreases opioid consumption, and improves recovery quality after breast surgery; and 2) determine which specific techniques(s) are safest and most effective.

\section{Methods}

\section{Search Strategy}

A systematic review of the literature was undertaken on July 25, 2014. Databases included were MEDLINE via PubMed, the Cochrane Library, and Web of Science's Core Collection (excluding MEDLINE) and SciELO Citation Index. The search was not limited by language or date. Searches combined terms for thoracic paravertebral blocks, breast surgery, and pain.

\section{PubMed search strategy:}

( (()((()((Nerve Block[mesh]) OR Analgesics, Opioid[mesh]) OR Anesthesia, General[mesh]) OR thoracic paravertebral block) OR PVB) OR PVBS) OR TPVB) OR TPVBS)) AND ((()((((Mastectomy[mesh]) OR Axilla/surgery[mesh]) OR Lymph Node Excision[mesh]) OR Sentinel Lymph Node Biopsy[mesh]) OR mastectomy) OR breast surgery) OR breast cancer surgery) OR breast conserving surgery) OR axillary dissection)))
AND $((()(()(((($ Pain[mesh]) OR Chronic Pain[mesh]) OR Pain, Postoperative[mesh]) OR Neuralgia[mesh]) OR Causalgia[mesh]) OR Somatosensory Disorders[mesh]) OR pain) OR chronic pain) OR postoperative pain) OR postsurgical pain) OR neuropathic) OR phantom pain)

In addition, we searched www.clinicaltrials.gov for ongoing studies. We then attempted to contact the corresponding author and asked for ongoing/accepted publications, however, this approach was not successful. EndNote X7 was used to combine and remove duplicate citations. This study is reported following the PRISMA guideline (10).

\section{Definition of Relevant Outcome}

Primary outcomes were (1) acute postoperative pain scores in the first 72 hours at rest and during movement; (2) opioid consumption: intraoperatively and during the initial 24 postoperative hours; and (3) incidence of chronic postsurgical pain.

Secondary outcomes were (1) incidence of nausea; (2) incidence of vomiting; (3) duration of hospital stay; and (4) block-related complications.

\section{Selection Criteria}

Two authors (AST and RST) screened the literature and selected the relevant articles. The search results were first screened to determine the eligible articles by reading the title and the abstract of each item. Full articles were sought for studies identified by this initial screen. The reviewers were not blinded to the authors of the selected studies. Inclusion and exclusion criteria were established a priori.

For our primary outcomes (pain intensity, opioid consumption, and incidence of chronic postsurgical pain), we restricted inclusion to prospective RCTs comparing TPVB to control as a main analgesic modality in patients having breast surgery. Control groups with no block, sham block, or block with saline under general anesthesia or sedation were acceptable. Trials that compared TPVB to other intervention techniques (e.g., local infiltration or other block) were excluded.

For secondary outcomes (e.g., nausea, vomiting, and length of hospital stay), both prospective RCTs and retrospective studies were considered eligible. Retrospective studies were included in the examination of secondary outcomes to increase the number of patients, as these outcomes were less frequently reported. To investigate procedure complications, prospective RCTs, retrospective studies, and case series were all considered eligible. 


\section{Data Extraction}

Two authors (AST and RST) independently extracted the relevant data from articles that met the selection criteria, and their results were compared to maintain accuracy. If differences were observed, the article was reviewed again. Data collected included: author names; year of publication; language in which the article was written; country in which the study took place; type of surgery; description of techniques and drugs used in the TPVB group; type of control group; additional postoperative analgesia; prophylactic anti-emetic use; pain scores in the first 2 hours, 24 hours, 48 hours, and 72 hours at rest and at movement (if unspecified, pain was assumed to have been assessed at rest); morphine equivalent opioid consumption during surgery, in the first 2 hours, and 24 hours, incidence and time of chronic postsurgical pain (CPSP); incidence of nausea, vomiting, procedure complications; and duration of hospital stay (in hours).

Among studies meeting our selection criteria, postoperative acute pain was assessed either using the visual analogue scale (VAS), ranging from 0 to 100 , or the numeric rating scale (NRS), ranging from 0 to 10 . All pain scores were converted to the NRS pain score, ranging from 0 to 10. If pain scores were not reported in the time frame that we designated (e.g., at 24 hours), average pain scores reported during the relevant period were used.

Opioids were converted to morphine equivalent using a standardized conversion calculator (11). Variables that were reported only graphically (e.g., pain scores) were estimated by manual measurements of the corresponding figures. For studies in which incidences of nausea and/or vomiting were not reported separately, but were reported as incidences of postoperative nausea and vomiting (PONV), such events were coded as nausea incidences. For studies in which the number of anti-emetics used was reported instead of incidences of nausea and/or vomiting, the number of anti-emetic was coded as incidences of vomiting.

In studies that only reported median and interquartile (IQR), we assumed that the mean was close to the median, therefore we took the value of median as a mean, and calculated the standard deviation (SD) as (IQR/1.35) (12). For studies that reported only mean without SD, we imputed the SD using the average SD from the remaining studies with no missing SDs (13).

\section{Assessment for Risk of Bias}

The risk of bias was assessed using the Cochrane Collaboration's risk of bias assessment tool (14). Two independent authors (AST and AS) assessed each trial and differences were resolved by consensus.

\section{A Priori Hypothesis for Sources of Variability in Effect Sizes}

Because studies used different techniques, we considered the hypothesis that variability among techniques contributed to heterogeneity across studies. As such, we examined the extent to which various techniques modulated the effect of TPVB. For outcomes of postoperative acute pain and opioid consumption, the following moderators (factors) were examined: (1) the number of block levels: single versus multiple; (2) whether blocks were anatomically or ultrasoundguided; (3) single injection versus infusion; (4) type of drug used; (5) addition of epinephrine to the mixture; (6) the addition of fentanyl to the mixture; and (7) use of nitrous oxide. No moderator testing was planned for CPSP meta-analysis, as the number of included studies was limited.

For outcomes of nausea and vomiting, we examined moderating effects of: (1) addition of fentanyl to the mixture; (2) use of prophylactic anti-emetics; and (3) use of nitrous oxide. For analysis of procedure complications, we considered the moderating effects of: (1) anatomically versus ultrasound-guided block; and (2) single versus multiple-level blocks.

\section{Data Analysis}

We used random-effects (RE) models to determine the overall intervention effect, taking into account heterogeneity among true effects of TVPB versus control. The assumption in RE models is that the true effect sizes vary among studies, and the technique is thus recommended when heterogeneity is present $(15,16)$. For continuous outcomes (e.g., acute pain, opioid consumption), the overall pooled estimates were reported as weighted standardized mean difference (SMD) with $95 \%$ confidence intervals $(\mathrm{Cl})$, to take into account the differences in sample sizes across studies (17). The SMD transforms all effect sizes to a common metric, and thus enables including different outcome measures in the same analysis (13). For dichotomous outcomes (e.g., incidences of nausea and vomiting), the pooled estimates were reported as odds ratio (OR) with $95 \%$ Cl.

We assessed heterogeneity using the Cochran's $\mathrm{Q}$ (18) and the I statistic (19). The Cochran's $\mathrm{Q}$ is the sum of the squared deviations of each study's estimate from the overall meta-analytic estimate, weighing 
each study similarly as in the meta-analysis. Cochran's $\mathrm{Q}$ is then compared with a $\chi 2$ distribution with $\mathrm{k}-1$ degrees of freedom (where $k=$ the number of studies). If Cochran's $Q$ is significantly larger than the corresponding $\chi 2$ statistic, it suggests that some studies evaluate different effects. In other words, that there is heterogeneity of the true effects among studies. Heterogeneity was also estimated using 12 , which is the proportion of total variance in the true effects across studies that can be attributed to true effect differences, rather than chance (i.e., sampling error). Larger 12 values indicate increasing heterogeneity among studies, whereas smaller 12 values indicate less heterogeneity. The corresponding estimated coefficients $(\beta)$ indicate the mean differences in the estimated effects between TVPB and control groups.

To test the extent to which study-level variables (e.g., the number of block levels, block technique) influence the size of the average true effects (i.e., the effect of TVPB versus control), study-level variables were included as moderators (covariates) in the mixed-effects models.( Mixed-effects (ME) model is also known as meta-regression models.) The model estimates heterogeneity among the true effects that does not result from study-level variables, accounting for moderators.

The proportion of heterogeneity accounted for by the study-level variables is provided by the R2 index. Larger R2 values suggest that the moderator included accounts for a large proportion of the heterogeneity of the estimated effects. To test for differences between levels of the moderator, an omnibus test (QM) was also computed in our mixed-effects model. The P-value obtained is the proportion of times that the QM is extreme or more extreme than the actually observed one. The corresponding estimated coefficients $(\beta)$ indicate the mean differences in the estimated effects between a specific level and the reference category (intercept) (20).

\section{Publication Bias Assessment}

If study reporting is biased (e.g., only studies with large and/or significant findings are published), the observed true effects may be related to the sample sizes, sampling variances, and/or standard errors, resulting in asymmetric funnel plots (21). We explored the presence of funnel plot asymmetry in the RE models due to standard errors using regression tests (22), as an indication of bias (23).

Analyses were performed using Review Manager (RevMan Version 5.3. Copenhagen: The Nordic Cochrane Centre, The Cochrane Collaboration, 2014), and the metafor package version 1.9-4 (20) in R statistical software version 3.1.1 (The R Foundation for Statistical Computing, Vienna, Austria).

\section{Results}

\section{Studies Selection and Characteristics}

We found 426 citations: 293 citations from PubMed, 123 from Cochrane, and 10 from the Web of Science. A PRISMA flow diagram is presented in Fig. 1. Twentyfour randomized clinical trials were included in the current meta-analysis; 22 in the English language, one in Spanish, and one in Russian. Of the studies included, 4 were from the US, 3 from Ireland, 2 from Finland, 2 from India, one from Canada, one from Australia, one from China, one from Egypt, one from Lebanon, one from Iran, one from Netherlands, one from Russia, one from Denmark, one from Thailand, one from Taiwan, one from Spain, and one was multi-national (Table 1). Attempts to contact authors to clarify or ask for unpublished data were mostly unsuccessful. We did, though, include unpublished data from Wu et al (24) in our analysis of nausea, vomiting, and length of hospital stay.

\section{Risk of Bias Assessment}

Among the included studies, the most frequently found bias was performance bias; only 6 studies (out of 24) were blinded (Fig. 2).

\section{Acute Postoperative Pain}

\section{Overall Intervention Effects}

Data from 22 RCTs $(9,24-46)$, including 1,714 patients (915 in the TPVB group and 799 in the control group), were used for the meta-analyses of acute postoperative pain. Only 7 studies reported pain scores after the first 24 hours $(9,26,28,33,34,39,45)$, and only 8 studies reported pain with movement $(9,28,31,33,34,40$ 42). Forest plots of the estimated main effect sizes are available in the appendix, while the main findings are summarized below.

Pain at rest was modestly but statistically significantly less for patients in the TPVB group than for those in the control group during the first 2 hours after surgery $(\mathrm{SMD}=-1.24,95 \% \mathrm{Cl}=-1.58$ to $-0.90, P<0.0001)$, the first 24 hours (SMD $=-0.89,95 \% \mathrm{Cl}=-1.29$ to $-0.49, P$ $<0.0001)$, the first 48 hours (SMD $=-1.07,95 \% \mathrm{Cl}=-2.20$ to $0.04, P<0.0001$ ), and the first 72 hours (SMD $=-0.60$, $95 \% \mathrm{Cl}=-1.17$ to $-0.03, P<0.0001)$. The tests for het- 


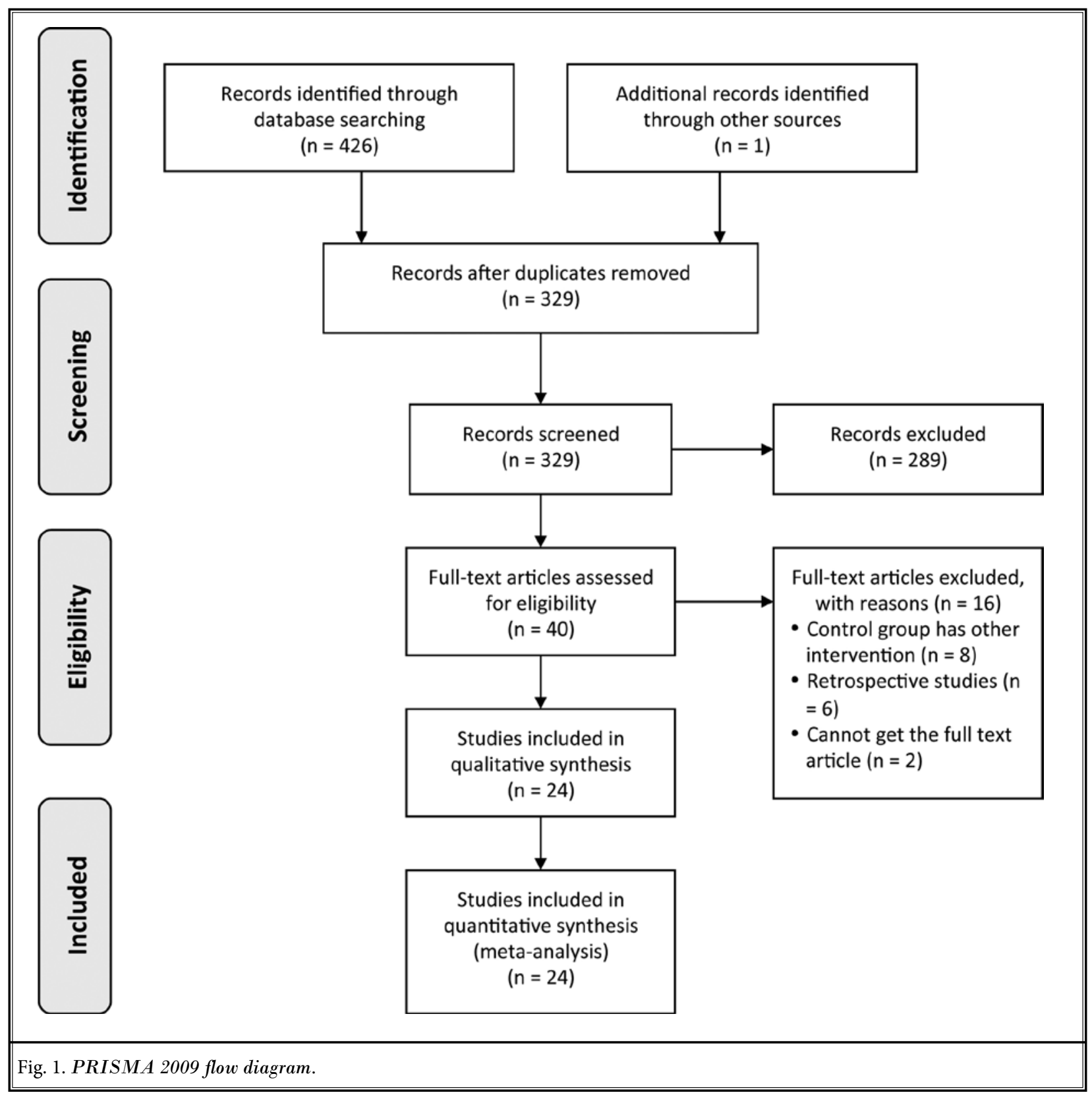

erogeneity for the models were significant, suggesting variability of the true effects for pain at rest between TPVB and control among studies (Table 2).

Pain at movement similarly was modestly but statistically significantly less for patients in the TPVB group than for those in the control group during the first 2 hours after surgery $(\mathrm{SMD}=-1.04,95 \% \mathrm{Cl}=-1.85$ to -0.22 , $P=0.013)$, the first 24 hours (SMD $=-1.35,95 \% \mathrm{Cl}=-1.93$ to $-0.77, P<0.0001$ ), the first 48 hours (SMD $=-2.32$, $95 \% \mathrm{Cl}=-4.17$ to $-0.47, P=0.014)$, and the first 72 hours
$(\mathrm{SMD}=-1.97,95 \% \mathrm{Cl}=-3.57$ to $-0.37, P=0.016)$. The tests for heterogeneity for the models were significant, suggesting variability of the true effects for pain at movement between TPVB and control among studies (Table 3).

\section{Moderator Analyses}

Since the potencies of the drugs are different (e.g., ropivacaine is less potent than bupivacaine when used at the same concentration and doses) (48), and since 
Table 1. Summary of the enrolled RCTs.

\begin{tabular}{|c|c|c|c|c|}
\hline Author(s)/year & $\begin{array}{l}\text { Number } \\
\text { of } \\
\text { patients }\end{array}$ & TPVB techniques used & TPVB drugs used & $\begin{array}{l}\text { Control and } \\
\text { adjuvant } \\
\text { medications }\end{array}$ \\
\hline $\begin{array}{l}\text { 1) Pusch et al } \\
\text { (1999) (25) }\end{array}$ & $\begin{array}{l}\mathrm{T}=44 \\
\mathrm{C}=42\end{array}$ & $\begin{array}{l}\text { Anatomical landmark, } \\
(\mathrm{E} \& W)^{\star *} \text { technique, single } \\
\text { injection at } \mathrm{T} 4\end{array}$ & Bupivacaine $0.5 \%(0.3 \mathrm{~mL} / \mathrm{kg})$ with Epi & GA with TIVA \\
\hline $\begin{array}{l}\text { 2) Klein et al } \\
\text { (2000) (26) }\end{array}$ & $\begin{array}{l}\mathrm{T}=30 \\
\mathrm{C}=30\end{array}$ & $\begin{array}{l}\text { Anatomical landmark, } \\
\text { multiple at } \mathrm{T} 1-7\end{array}$ & Bupivacaine $0.5 \%(4 \mathrm{~mL}) /$ level with Epi & Propofol sedation \\
\hline $\begin{array}{l}\text { 3) Terheggen et al } \\
\text { (2002) (27) }\end{array}$ & $\begin{array}{l}\mathrm{T}=15 \\
\mathrm{C}=15\end{array}$ & $\begin{array}{l}\text { Anatomical landmark, } \\
(\mathrm{E} \& \mathrm{~W})^{* *} \text { technique, catheter } \\
\text { at } \mathrm{T} 3-4 \text { space }\end{array}$ & $\begin{array}{l}\text { Bupivacaine } 0.5 \%(15-20 \mathrm{~mL}) \text {, with Epi } \\
\text { Infusion thought surgery }\end{array}$ & Propofol sedation \\
\hline $\begin{array}{l}\text { 4) Naja et al (2003) } \\
\text { (28) }\end{array}$ & $\begin{array}{l}\mathrm{T}=30 \\
\mathrm{C}=30\end{array}$ & $\begin{array}{l}\text { Anatomical landmark with } \\
\text { nerve stimulator, multiple } \\
\text { injections at T2-5 for SM, } \\
\text { T2-4 for PM, T1-5 for MRM. }\end{array}$ & $\begin{array}{l}\text { Lidocaine } 2 \% \text {, bupivacaine } 0.5 \% \text {, fentanyl, clonidine } \\
\text { and Epi }\end{array}$ & Propofol sedation \\
\hline $\begin{array}{l}\text { 5) Kairaluoma et al } \\
\text { (2004) (29) }\end{array}$ & $\begin{array}{l}\mathrm{T}=30 \\
\mathrm{C}=30\end{array}$ & $\begin{array}{l}\text { Anatomical, loss of resistance, } \\
\text { single injection at } \mathrm{T} 3\end{array}$ & Bupivacaine $0.3 \mathrm{~mL} / \mathrm{kg}$ & $\begin{array}{l}\text { GA with } \\
\text { sevoflurane }\end{array}$ \\
\hline $\begin{array}{l}\text { 6) Buggy \& Kerin } \\
(2004)(30)\end{array}$ & $\begin{array}{l}\mathrm{T}=10 \\
\mathrm{C}=10\end{array}$ & $\begin{array}{l}\text { Anatomical landmark, at } \mathrm{T} 3 \\
\text { or } 4 \text { space }\end{array}$ & $\begin{array}{l}\text { Levobupivacaine } 0.25 \% \text { bolus followed by infusion } \\
\text { for } 24 \text { hours }\end{array}$ & $\begin{array}{l}\text { GA with isoflurane } \\
\text { and nitrous oxide }\end{array}$ \\
\hline $\begin{array}{l}\text { 7) Burlacu et al } \\
\text { (2006) (31) }\end{array}$ & $\begin{array}{l}\mathrm{T}(\mathrm{a})=13 \\
\mathrm{~T}(\mathrm{~b})=13 \\
\mathrm{~T}(\mathrm{c})=12 \\
\mathrm{C}=14\end{array}$ & $\begin{array}{l}\text { Anatomical landmark, catheter } \\
\text { at } \mathrm{T} 3 \text {, infusion for } 48-72 \mathrm{hr}\end{array}$ & $\begin{array}{l}\mathrm{T} \text { (a): levobupivacaine } 0.25 \% \text { plus } 1 \mathrm{~mL} \text { normal } \\
\text { saline, followed by infusion of levobupivacaine } 0.1 \% \\
\mathrm{~T}(\mathrm{~b}) \text { : levobupivacaine } 0.25 \% \text { plus fentanyl } 50 \mathrm{mcg} \text {, } \\
\text { followed by infusion of levobupivacaine } 0.05 \% \text { with } \\
\text { fentanyl } \\
\mathrm{T} \text { (c): levobupivacaine } 0.25 \% \text { with clonidine } 150 \\
\text { mcg, followed by infusion of levobupivacaine } 0.05 \% \\
\text { with clonidine }\end{array}$ & $\begin{array}{l}\text { GA with } \\
\text { sevoflurane and } \\
\text { nitrous oxide }\end{array}$ \\
\hline $\begin{array}{l}\text { 8) Kairaluoma et al } \\
(2006)^{*}(32)\end{array}$ & $\begin{array}{l}\mathrm{T}=30 \\
\mathrm{C}=30\end{array}$ & $\begin{array}{l}\text { Anatomical, loss of resistance, } \\
\text { single injection at } \mathrm{T} 3\end{array}$ & Bupivacaine $0.3 \mathrm{~mL} / \mathrm{kg}$ & $\begin{array}{l}\text { GA with } \\
\text { sevoflurane }\end{array}$ \\
\hline $\begin{array}{l}\text { 9) Iohom et al } \\
(2006)^{*}(33)\end{array}$ & $\begin{array}{l}\mathrm{T}=14 \\
\mathrm{C}=15\end{array}$ & $\begin{array}{l}\text { Anatomical, loss of resistance, } \\
\text { catheter at } \mathrm{T} 3\end{array}$ & $\begin{array}{l}\text { Bupivacaine } 0.25 \%(10 \mathrm{~mL} / 12 \mathrm{hr}) \text { up to } 48 \text { hours } \\
\text { postoperatively }\end{array}$ & $\begin{array}{l}\text { GA with } \\
\text { sevoflurane and } \\
\text { nitrous oxide }\end{array}$ \\
\hline $\begin{array}{l}\text { 10) Shkol'nik et al } \\
(2006)(34)\end{array}$ & $\begin{array}{l}\mathrm{T}=90 \\
\mathrm{C}=90\end{array}$ & $\begin{array}{l}\text { Anatomical, loss of resistance, } \\
\text { multiple levels from C7-T6. }\end{array}$ & $\begin{array}{l}\text { Bupivacaine } 0.125 \% \text { / Ropivacaine } 0.2 \% 4-5 \mathrm{~mL} \text { at } \\
\text { each level }\end{array}$ & GA with TIVA \\
\hline $\begin{array}{l}\text { 11) Dabbagh } \\
\text { \&Elyasi (2007) } \\
(35)\end{array}$ & $\begin{array}{l}\mathrm{T}=30 \\
\mathrm{C}=30\end{array}$ & $\begin{array}{l}\text { Anatomical, loss of resistance, } \\
\text { single at T4 }\end{array}$ & Lidocaine $2 \%(15 \mathrm{~mL})$ & $\begin{array}{l}\text { GA halothane with } \\
\text { nitrous oxide }\end{array}$ \\
\hline $\begin{array}{l}\text { 12) Moller et al } \\
(2007)(36)\end{array}$ & $\begin{array}{l}\mathrm{T}=38 \\
\mathrm{C}=41\end{array}$ & $\begin{array}{l}\text { Anatomical, multiple levels } \\
\text { from C7-T5 }\end{array}$ & Ropivacaine $0.5 \%(30 \mathrm{~mL})$ & GA with TIVA \\
\hline $\begin{array}{l}\text { 14) Boughey et al } \\
\text { (2009) (37) }\end{array}$ & $\begin{array}{l}\mathrm{T}=39 \\
\mathrm{C}=41\end{array}$ & $\begin{array}{l}\text { Anatomical, loss of resistance, } \\
\text { multiple levels from T1-T6 }\end{array}$ & Ropivacaine $1 \%$ and $0.5 \%$ with Epi & GA \\
\hline $\begin{array}{l}\text { 15) Arunakul \& } \\
\text { Ruksa (2010) (38) }\end{array}$ & $\begin{array}{l}\mathrm{T}=10 \\
\mathrm{C}=10\end{array}$ & Anatomical, single level at $\mathrm{T} 4$ & Bupivacaine $0.5 \% 3 \mathrm{~mL} / \mathrm{kg}$ & $\begin{array}{l}\text { GA with isoflurane } \\
\text { and nitrous oxide }\end{array}$ \\
\hline $\begin{array}{l}\text { 16) Buckenmaier } \\
\text { et al (2010) (39) }\end{array}$ & $\begin{array}{l}T(a)=26 \\
T(b)=26 \\
C=21\end{array}$ & $\begin{array}{l}\text { Anatomical, single at } \mathrm{T} 3 \\
\text { infusion for } 72 \text { hours }\end{array}$ & $\begin{array}{l}\mathrm{T}(\mathrm{a}) \text { : ropivacaine } 0.1 \% \\
\mathrm{~T}(\mathrm{~b}) \text { : ropivacaine } 0.2 \%\end{array}$ & GA \\
\hline $\begin{array}{l}\text { 17) Jehan \& Abdel- } \\
\text { halim (2011) (40) }\end{array}$ & $\begin{array}{l}\mathrm{T}=20 \\
\mathrm{C}=20\end{array}$ & $\begin{array}{l}\text { Anatomical, loss of resistance, } \\
\text { nerve stimulator, single at } \mathrm{T} 4\end{array}$ & $\begin{array}{l}\text { Lidocaine } 2 \% \text { (with Epi) bolus then infusion with } \\
\text { lidocaine } 1 \% \text { at rate of } 5 \mathrm{~mL} / \mathrm{hr}\end{array}$ & GA with isoflurane \\
\hline $\begin{array}{l}\text { 18) Li et al (2011) } \\
\text { (41) }\end{array}$ & $\begin{array}{l}\mathrm{T}=15 \\
\mathrm{C}=25\end{array}$ & $\begin{array}{l}\text { Ultrasound-guided, multiple } \\
\text { levels from T2-5 }\end{array}$ & Bupivacaine $0.5 \%$ with Epi, $3-5 \mathrm{~mL}$ at each level & $\begin{array}{l}\text { GA with } \\
\text { desflurane }\end{array}$ \\
\hline $\begin{array}{l}\text { 19) Ibarra et al } \\
(2011)^{*}(42)\end{array}$ & $\begin{array}{l}\mathrm{T}=15 \\
\mathrm{C}=14\end{array}$ & $\begin{array}{l}\text { Anatomical, nerve stimulator, } \\
\text { single level }\end{array}$ & Ropivacaine & GA \\
\hline $\begin{array}{l}\text { 20) Bhuvaneswari } \\
\text { et al (2012) (43) }\end{array}$ & $\begin{array}{l}\mathrm{T}(\mathrm{a})=12 \\
\mathrm{~T}(\mathrm{~b})=12 \\
\mathrm{~T}(\mathrm{c})=12 \\
\mathrm{C}=12\end{array}$ & Anatomical, single at $\mathrm{T} 3$ & $\begin{array}{l}\mathrm{T}(\mathrm{a}) \text { : bupivacaine } 0.25 \%+\text { Epi } \\
\mathrm{T}(\mathrm{b}) \text { : bupivacaine } 0.25 \%+\mathrm{Epi}+\text { fentanyl } \\
\mathrm{T} \text { (c): bupivacaine } 0.5 \%+\text { Epi }\end{array}$ & GA \\
\hline
\end{tabular}


Table 1 (cont.). Summary of the enrolled RCTs.

\begin{tabular}{|c|c|c|c|c|}
\hline Author(s)/year & $\begin{array}{l}\text { Number } \\
\text { of } \\
\text { patients }\end{array}$ & TPVB techniques used & TPVB drugs used & $\begin{array}{l}\text { Control and } \\
\text { adjuvant } \\
\text { medications }\end{array}$ \\
\hline $\begin{array}{l}\text { 20) Das et al } \\
\text { (2012) (44) }\end{array}$ & $\begin{array}{l}\mathrm{T}=30 \\
\mathrm{C}=30\end{array}$ & $\begin{array}{l}\text { Anatomical, multiple levels } \\
\text { from T3-6 }\end{array}$ & Bupivacaine $0.5 \% 5 \mathrm{~mL}$ at each level & $\begin{array}{l}\text { GA volatile with } \\
\text { nitrous oxide }\end{array}$ \\
\hline $\begin{array}{l}\text { 21) Abdallah et al } \\
\text { (2014) (45) }\end{array}$ & $\begin{array}{l}\mathrm{T}=33 \\
\mathrm{C}=31\end{array}$ & $\begin{array}{l}\text { Ultrasound-guided } \\
\text { (hydrolocation technique), } \\
\text { Multiple levels T1-5 }\end{array}$ & Ropivacaine $0.5 \%$ (total $25 \mathrm{~mL}$ ) & $\begin{array}{l}\text { GA with } \\
\text { sevoflurane and } \\
\text { nitrous oxide }\end{array}$ \\
\hline $\begin{array}{l}\text { 22) Ilfeld et al } \\
\text { (2014) (46) }\end{array}$ & $\begin{array}{l}\mathrm{T}=30 \\
\mathrm{C}=30\end{array}$ & $\begin{array}{l}\text { Ultrasound-guided, single at } \\
\text { T3-4, catheter inserted }\end{array}$ & Ropivacaine $0.5 \%$ with Epi & GA \\
\hline $\begin{array}{l}\text { 23) Karmakar et al } \\
(2014)^{*}(9)\end{array}$ & $\begin{array}{l}\mathrm{T}(\mathrm{a})=60 \\
\mathrm{~T}(\mathrm{~b})=57 \\
\mathrm{C}=60\end{array}$ & $\begin{array}{l}\text { Anatomical, single injection } \\
\text { at T3 followed by infusion for } \\
72 \text { hours }\end{array}$ & $\begin{array}{l}\mathrm{T} \text { (a): ropivacaine } 2 \mathrm{mg} / \mathrm{kg} \text { with Epi }(5 \mu \mathrm{g} / \mathrm{mL}) \text { then } \\
\text { infusion of } 0.9 \% \text { saline } \\
\mathrm{T} \text { (b): ropivacaine } 2 \mathrm{mg} / \mathrm{kg} \text { with Epi }(5 \mu \mathrm{g} / \mathrm{mL}) \text { then } \\
0.25 \% \text { ropivacaine at } 0.1 \mathrm{~mL} / \mathrm{kg} / \mathrm{hr}\end{array}$ & GA with TIVA \\
\hline $\begin{array}{l}\text { 24) Wu et al (2015) } \\
\text { (24) }\end{array}$ & $\begin{array}{l}\mathrm{T}=187 \\
\mathrm{C}=199\end{array}$ & $\begin{array}{l}\text { Anatomical, multiple levels, or } \\
\text { catheter infusion: either with } \\
\text { a T } 2-4 \text { catheter or multi-level } \\
\text { injections from T } 1 \text { to } 5 .\end{array}$ & $\begin{array}{l}\text { Bupivacaine } 0.5 \% \text { or ropivacaine } 0.5 \% \text { with Epi. } \\
\text { When a multi-level technique was used, ropivacaine } \\
0.75 \%, 5 \mathrm{~mL} \text {, was given at each of the } 5 \text { levels } \\
\text { When infusion: } 6-10 \mathrm{~mL} / \mathrm{h} \text { of either solution up to } \\
48 \text { hours }\end{array}$ & $\begin{array}{l}\text { GA with } \\
\text { sevoflurane }\end{array}$ \\
\hline
\end{tabular}

${ }^{*}$ Studies reporting chronic post-surgical pain. ${ }^{* *}$ E\&W: Eason and Wyatt technique (47).

$\mathrm{TPVB}=$ thoracic paravertebral block, $\mathrm{T}=$ thoracic paravertebral block group, $\mathrm{C}=$ control group, TIVA $=$ total intravenous anesthesia, $\mathrm{GA}=$ general anesthesia, $\mathrm{Epi}=$ epinephrine, $\mathrm{SM}=$ simple mastectomy, $\mathrm{PM}=$ partial mastectomy, $\mathrm{MRM}=$ modified radical mastectomy

the concentration and doses used were not always mentioned in the studies under consideration, we excluded drug comparisons from the moderator analysis.

Pain at rest: The use of fentanyl in the block mixture was found to moderate the effect of TPVB at the first 24, 48, and 72 hours; studies that used fentanyl reported less acute pain at rest for the TPVB group than for the control group (Table 2). The other potential moderators did not significantly affect acute postoperative pain at rest. Fig. 3 illustrates how these factors affect the efficacy of TPVB.

\section{Pain at Movement}

The use of fentanyl in the block mixture was found to moderate the effect of TPVB in the first 24 and 72 hours; studies that used fentanyl reported less acute pain at movement for the TPVB group than for the control group. The use of multiple-level blocks was found to moderate the effect of TPVB in the first 24, 48 , and 72 hours; studies that used multiple-level blocks reported less acute pain at movement for the TPVB group than for the control group (Table 3). The other potential moderators did not significantly affect acute postoperative pain at movement. Fig. 4 illustrates how these factors affect the efficacy of TPVB.

\section{Opioid Consumption}

Data from 16 RCTs $(9,24,26,29-31,34-36,38,40,41,43-$
46), including 1,406 patients (744 in the TPVB group and 662 in the control group), were used in the metaanalysis of opioid consumption. Eleven studies reported the intraoperative opioid used, 7 studies reported opioid used in the first 2 hours (post-anesthesia care unit), and 9 studies described the consumption of opioids in the first 24 hours. Forest plots of the estimated main effect sizes are available in the appendix, while the main findings are summarized below.

Intraoperative opioid consumption (in $\mathrm{mg}$ ) was statistically significantly less for patients in the TPVB group as compared with those in the control group (SMD = $-1.03,95 \% \mathrm{Cl}=-1.45$ to $-0.60, P<-.0001)$, with significant heterogeneity $(I 2=89.73 \%, Q=101.60, P=<0.0001)$. Postoperative opioid consumption (in $\mathrm{mg}$ morphine equivalent) was significantly lower for patients in the TPVB group than those in the control group in the first 2 hours (SMD $=-0.62,95 \% \mathrm{Cl}=-0.99$ to $-0.25, P=0.001)$, with significant heterogeneity $(I 2=75.42 \%, Q=26.04$, $P=0.0005)$ and the first 24 hours (SMD $=-1.90,95 \% \mathrm{Cl}$ $=-2.83$ to $-0.96, P<0.0001)$, with significant heterogeneity $(12=95 \%, Q=274, P<0.0001)$. None of these differences is likely to be clinically important.

Of the moderators tested, only nitrous oxide (N2O) had a statistical effect on intraoperative opioid consumption: $\mathrm{SMD}=-1.52,95 \% \mathrm{Cl}=-2.13$ to -0.91 in patients who had $\mathrm{N} 2 \mathrm{O}$ versus $\mathrm{SMD}=-0.71,95 \% \mathrm{Cl}=$ -1.19 to -0.23 in patients who did not have N2O. Tests 


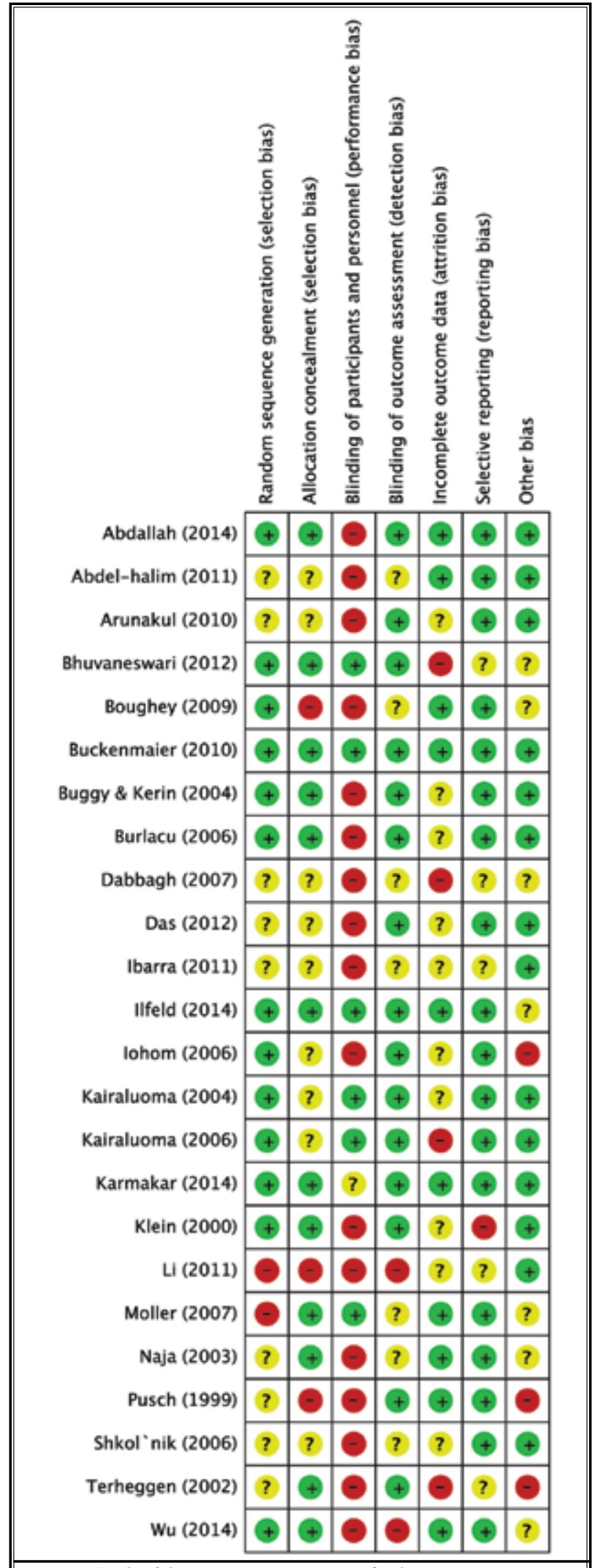

Fig. 2. Risk of bias assessment using Cochrane criteria. for heterogeneity: $1287.16 \%, Q=83, P=<0.0001, R 2$ $=23.19$. Moderator statistics: $\beta=-0.813(95 \% \mathrm{Cl}=-1.59$ to -0.03$), P=0.040$ and on opioid consumption during the first 2 hours postoperatively: SMD $=-1.57,95 \% \mathrm{Cl}$ -2.41 to -0.74 in patients who had N2O versus SMD = $-0.43,95 \% \mathrm{Cl}=-0.74$ to -0.12 in patients who did not have N2O. Tests for heterogeneity: $I 2=61.95 \%, Q=19$, $P=0.014, \mathrm{R} 2=52.32$. Moderator statistics: $\beta=-1.142$ $(95 \% \mathrm{Cl}=-2.03$ to -0.25$), P=0.011$.

\section{Secondary Outcomes}

Data from 19 studies, 16 randomized clinical trials $(24,25,27-29,31,35-38,40,41,43-45)$ and 4 retrospective cohort studies (49-52), including 2,989 patients (1,486 in the TPVB group and 1,503 in the control group), were included in the meta-analysis for the quality of recovery (nausea, vomiting, and length of hospital stay). We also did a separate analysis for those outcomes from randomized clinical trials only, and we found overall similar conclusions (data not presented).

The use of TPVB was found to be associated with a decreased incidence of nausea $(O R=-0.83,95 \% \mathrm{Cl}=$ -1.17 to $-0.49, P<0.0001)$, with significant heterogeneity $(I 2=41.92 \%, Q=24.75, P=0.009)$, and decreased incidence of vomiting ( $O R=-0.87,95 \% \mathrm{Cl}=-1.39$ to $-0.34, P=0.001)$, with significant heterogeneity $(12=$ $52.13 \%, Q=19.18, P=0.013)$. The average length of hospital stay for patients in the TPVB group was statistically significantly less (SMD $=-0.60$ hour, $95 \% \mathrm{Cl}=-1.13$ to $-0.06, P=0.028$ ) than that in the control group, with significant heterogeneity $(12=94.37 \%, Q=50.32, P<$ 0.0001 ). However, this small difference is unlikely to be clinically important.

No moderators were found to have a significant effect in the efficacy of TPVB on nausea, vomiting, or the length of stay. Fig. 5 illustrates the effect of TPVB in incidences of nausea, vomiting, and length of hospital stay.

\section{Chronic Postsurgical Pain}

Data from 4 studies $(9,32,33,42)$, including 295 patients (176 in the TPVB group and 119 in the control group), were used in the meta-analyses for incidence of CPSP. Two studies reported the incidence at 3 months $(9,33)$, one at 5 months $(42), 2$ at 6 months $(9,32)$, and one at 12 months (32). Due to the limited number of studies available, incidences of CPSP reported at 5 months were treated as CPSP reported at 6 months. Results indicated a reduction in the incidence of CPSP at 6 months (RR 0.70 [0.49 to 0.99] $P=0.04$ ) but not at 3 months (RR 0.71 [0.45 to 1.13] $P=0.15$ ) for the 
Analgesic Efficacy and Safety of Thoracic Paravertebral Block for Breast Surgery

Table 2. Meta-analyses evaluating the effect of TVPB on acute pain (at rest) compared with control.

\begin{tabular}{|c|c|c|c|c|c|c|c|c|}
\hline & \multirow{2}{*}{ Model } & \multicolumn{4}{|c|}{ Test for heterogeneity } & \multicolumn{3}{|c|}{ Model/moderator statistics } \\
\hline & & I2 (\%) & $\mathbf{Q}$ & $\boldsymbol{P}$ & $\mathbf{R 2}$ & $\beta$ & $95 \%$ CI & $\boldsymbol{P}$ \\
\hline First 2 hours & $\mathrm{RE}$ & 87.39 & 110.35 & $<.0001$ & & -1.24 & {$[-1.58,-0.90]$} & $<.0001$ \\
\hline \multirow{2}{*}{ First 24 hours } & $\mathrm{RE}$ & 90.78 & 142.59 & $<.0001$ & & -0.89 & {$[-1.29,-0.49]$} & $<.0001$ \\
\hline & ME (fentanyl) a & 77.85 & 23.62 & $<.0001$ & 65.31 & -2.53 & {$[-3.55,-1.51]$} & $<.0001$ \\
\hline \multirow{2}{*}{ First 48 hours } & $\mathrm{RE}$ & 97.59 & 77.85 & $<.0001$ & & -1.08 & {$[-1.08,0.04]$} & 0.060 \\
\hline & ME (fentanyl) a & 69.61 & 42.99 & $<.0001$ & 95.07 & -4.05 & {$[-5.26,-2.84]$} & $<.0001$ \\
\hline \multirow{2}{*}{ First 72 hours } & $\mathrm{RE}$ & 91.50 & 51.35 & $<.0001$ & & -0.60 & {$[-1.66,-0.03]$} & 0.040 \\
\hline & ME (fentanyl) a & 71.94 & 15.90 & $<.0001$ & 77.91 & -2.11 & {$[-3.14,-1.07]$} & $<.0001$ \\
\hline
\end{tabular}

I2 = proportion of heterogeneity; $\mathrm{Q}=$ test statistic, test statistic for random effects model, test statistic for the omnibus test of coefficients for mixed effects model; $\beta=$ estimated coefficients (mean differences in the estimated effects); 2 = amount of heterogeneity accounted for; RE = random effects model; $\mathrm{ME}=$ mixed effects model. aThe estimated average acute pain score was lower for studies using fentanyl than those not using fentanyl.

Table 3. Meta-analyses evaluating the effect of TVPB on acute pain (at movement) compared with control.

\begin{tabular}{|c|c|c|c|c|c|c|c|c|}
\hline & \multirow{2}{*}{ Model } & \multicolumn{4}{|c|}{ Test for heterogeneity } & \multicolumn{3}{|c|}{ Model/moderator statistics } \\
\hline & & I2 (\%) & $\mathbf{Q}$ & $\boldsymbol{P}$ & $\mathbf{R 2}$ & $\beta$ & $95 \%$ CI & $\boldsymbol{P}$ \\
\hline \multirow[t]{3}{*}{ First 2 hours } & $\mathrm{RE}$ & 95.06 & 151.78 & $<.0001$ & & -1.04 & {$[-1.85,-0.22]$} & 0.013 \\
\hline & ME (level) a & 90.51 & 6.58 & 0.010 & 42.45 & 2.08 & {$[0.01,0.49]$} & 0.010 \\
\hline & ME (method) b & 93.11 & 5.30 & 0.021 & 34.93 & -2.75 & {$[-5.10,-0.41]$} & 0.021 \\
\hline \multirow[t]{2}{*}{ First 24 hours } & $\mathrm{RE}$ & 90.68 & 91.89 & $<.0001$ & & -1.35 & {$[-1.93,-0.77]$} & $<.0001$ \\
\hline & ME (fentanyl) c & 84.06 & 8.46 & 0.004 & 48.43 & -1.79 & {$[-2.99,-0.58]$} & 0.004 \\
\hline \multirow[t]{2}{*}{ First 48 hours } & $\mathrm{RE}$ & 98.42 & 187.92 & $<.0001$ & & -2.32 & {$[-4.17,-0.47]$} & 0.014 \\
\hline & ME (level) a & 76.31 & 45.47 & $<.0001$ & 94.64 & 3.63 & {$[2.58,4.69]$} & $<.0001$ \\
\hline \multirow[t]{3}{*}{ First 72 hours } & $\mathrm{RE}$ & 98.18 & 109.47 & $<.0001$ & & -1.97 & {$[-3.57,-0.37]$} & 0.016 \\
\hline & ME (fentanyl) c & 93.55 & 12.87 & 0.0003 & 78.45 & -3.88 & {$[-5.99,-1.76]$} & 0.0003 \\
\hline & ME (level) a & 94.74 & 6.40 & 0.011 & 60.30 & 2.73 & {$[0.62,4.85]$} & 0.011 \\
\hline
\end{tabular}

$\mathrm{I} 2$ = proportion of heterogeneity; $\mathrm{Q}=$ test statistic, test statistic for random effects model; test statistic for the omnibus test of coefficients for mixed effects model; $\beta$ = estimated coefficients (mean differences in the estimated effects); R2 = amount of heterogeneity accounted for; RE = random effects model; $\mathrm{ME}=$ mixed effects model.

aThe estimated average acute pain score was higher for studies using single level than those using multiple levels blocks.

bThe estimated average acute pain score was lower for studies using anatomical than those using ultrasound.

cThe estimated average acute pain score was lower for studies using fentanyl than those not using fentanyl.

TPVB group versus the control group (Fig. 6). Results suggested no statistically significant heterogeneity in these meta-analytic models. Nonetheless, the assessments of CPSP were inconsistent across studies, just as the time for diagnosis of CPSP was inconsistent across studies. The limited number of studies precluded us from examining the effect of moderators on TPVB.

\section{Complications}

Information of procedure complications was extracted from 26 studies; 18 RCTs, 5 retrospective cohort studies, and 3 case series. Table 4 summarizes the reported complications with covariates comparisons.

\section{Publication Bias}

In the present study, the presence of funnel plot asymmetry in the RE models was explored using regression tests (22). Results showed asymmetry in the funnel plots of the following RE models: acute pain at rest (first 2 hours, first 24 hours, and first 48 hours), acute pain at movement (first 72 hours), and opioid consumption (first 2 hours). Although it is premature 


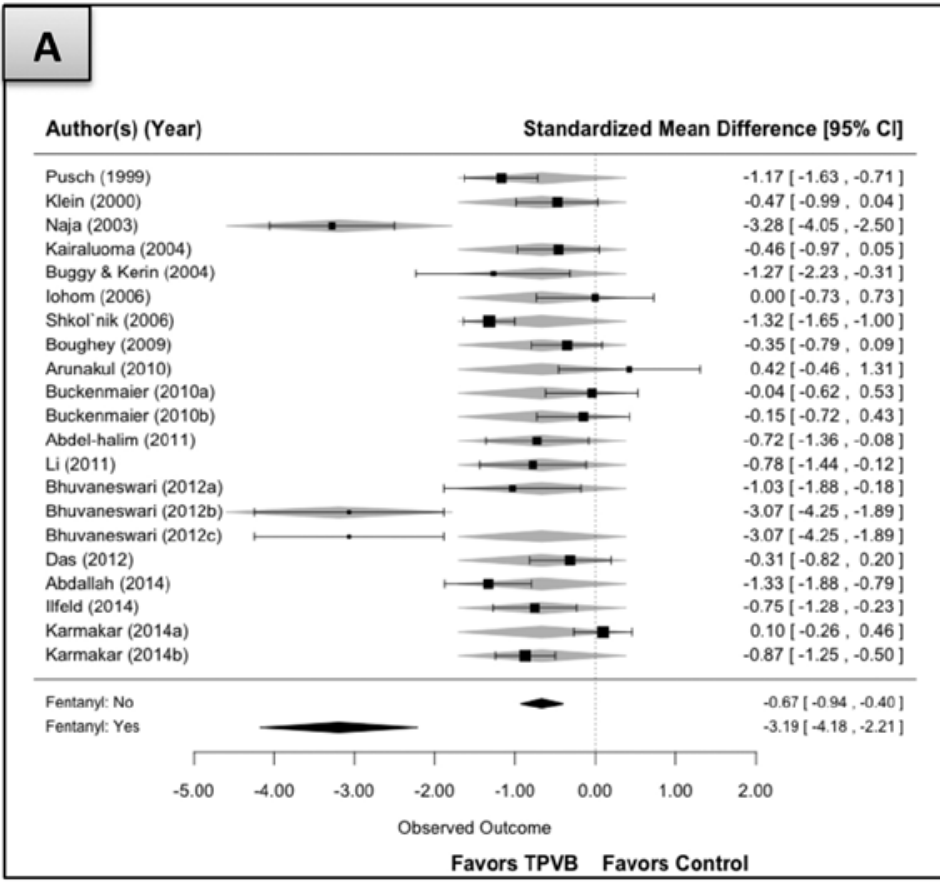

\section{B}

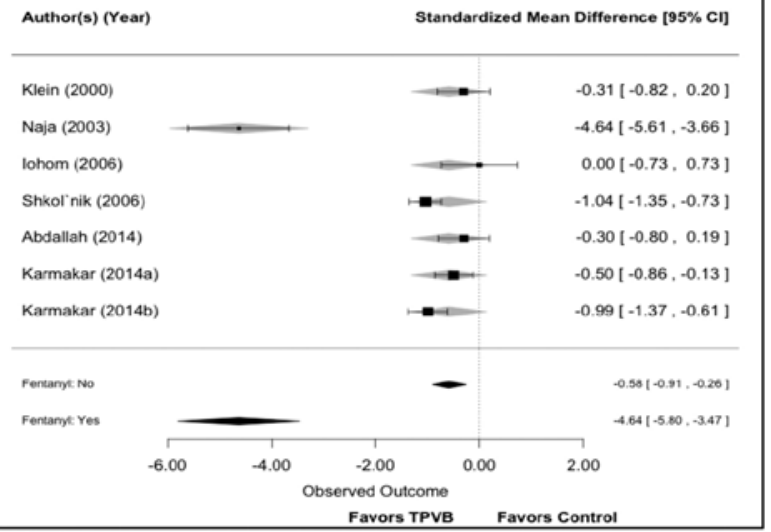

\section{C}

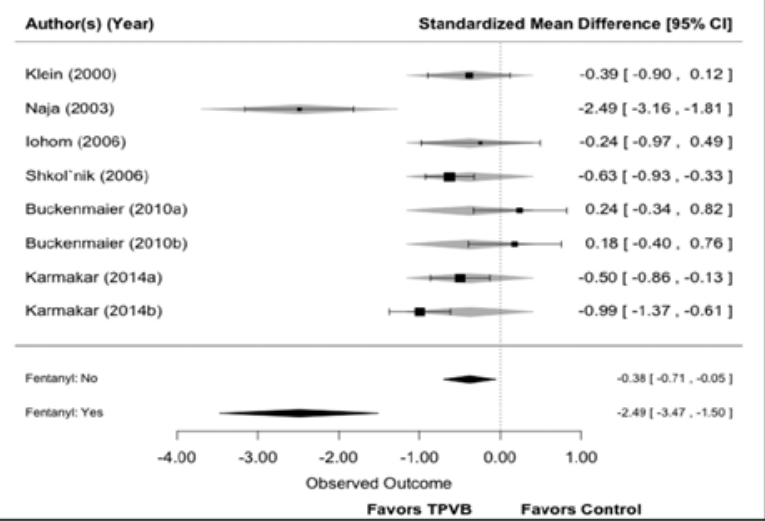

Fig. 3. Forest plots for pain scores at rest. (A) During the first 24 hours, (B) at 48 hours, (C) at 72 hours. Adding fentanyl to the mixture was used as moderator and should provide significant pain control in the first 72 hours. The observed effects, based on the random-effects model, are indicated with the black square with the outer edges indicating the $95 \%$ confidence interval limits. The size of each square is proportional with the weight of that particular study in the meta-analysis. The estimated effects of the moderator on each study, based on the mixed-effects model, are represented by the gray polygons. The black polygons at the bottom of each figure represent the overall estimated effect of the moderator.

to conclude that publication bias exists for these models, researchers should interpret results from these models with caution, as the pooled estimates may be biased.

\section{Discussion}

We found that use of TPVB for breast surgery reduced acute pain within the first 72 hours, both at rest and movement, even in studies that did not use 


\section{A}

Author(s) (Year) Standardized Mean Difference [95\% Cl]

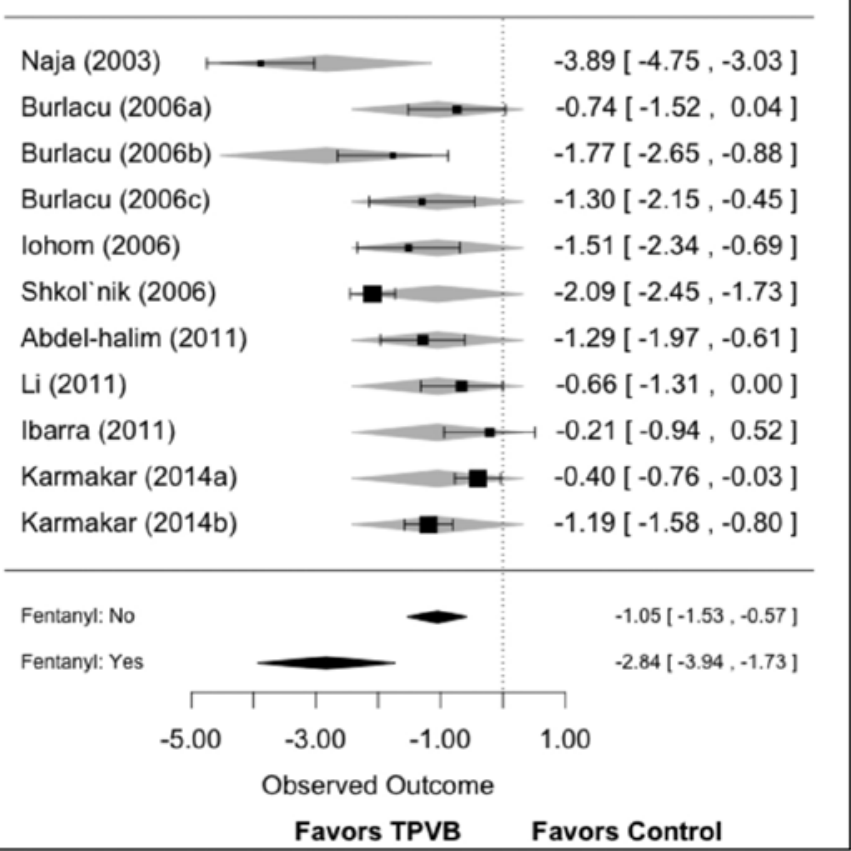

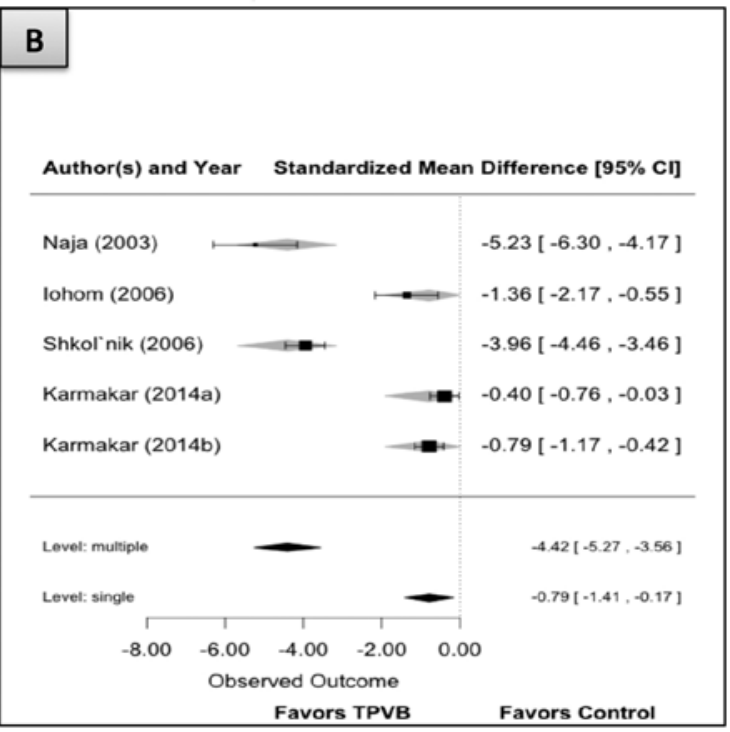

\section{C}

Author(s) (Year) Standardized Mean Difference [95\% Cl]

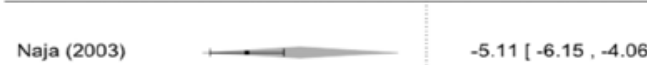

lohom (2006)

Shkol'nik (2006)

$\longrightarrow-1.45[-2.26,-0.63]$

Karmakar (2014a)

$-2.32[-2.70,-1.94]$

\begin{tabular}{lll} 
Karmakar (2014b) & $-0.79[-1.17,-0.42]$ \\
\hline
\end{tabular}

$-0.40[-0.76,-0.03]$

Level: mutiple

Level: single

$-3.59[-5.25,-1.94]$

Level. single

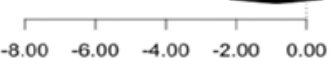

Observed Outcome

Favors TPVB

Favors Control

Fig. 4. Forest plots for pain scores at movement. (A) During the first 24 hours, (B) at 48 hours, (C) at 72 hours. Adding fentanyl to the mixture was selected as moderator in A, while using multiple levels block versus single was selected as moderator in $B$ and $C$. The observed effects, based on the random-effects model, are indicated with the black square with the outer edges indicating the $95 \%$ confidence interval limits. The size of each square is proportional with the weight of that particular study in the meta-analysis. The estimated effects of the moderator on each study, based on the mixed-effects model, are represented by the gray polygons. The black polygons at the bottom of each figure represent the overall estimated effect size for the moderator. 


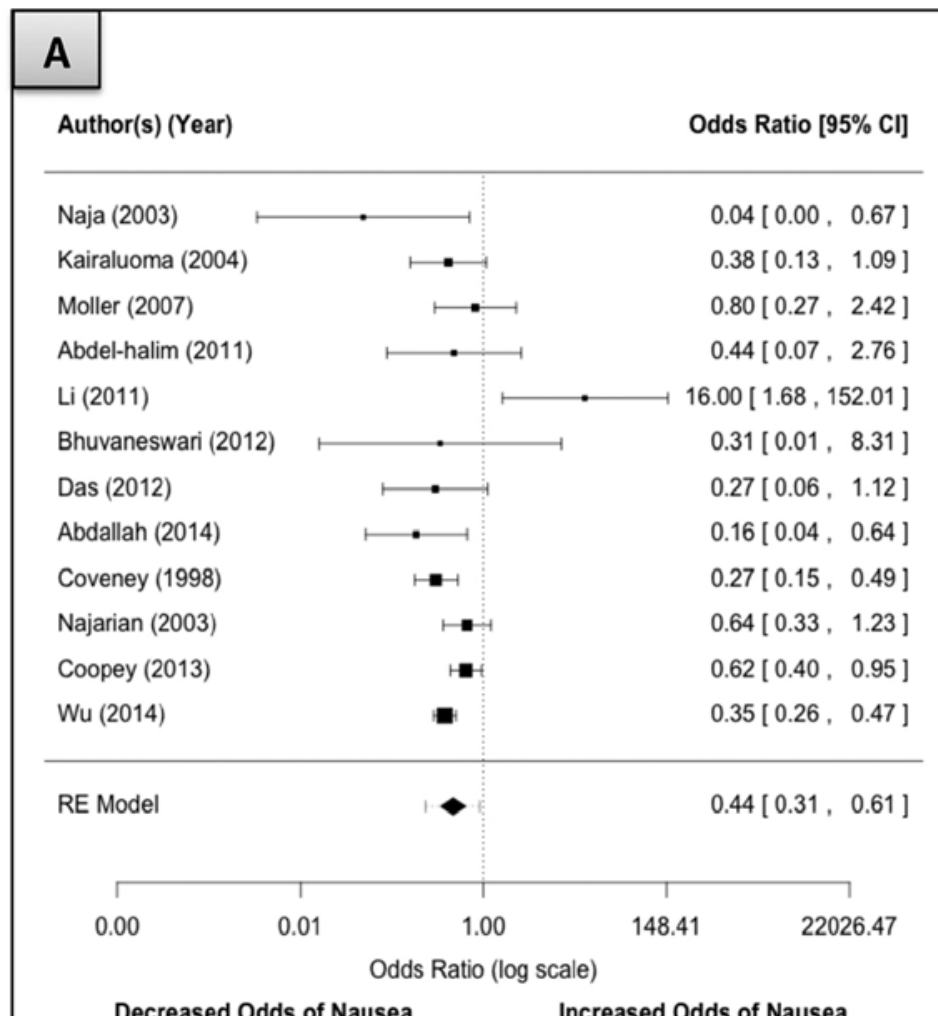

Decreased Odds of Nausea

Increased Odds of Nausea

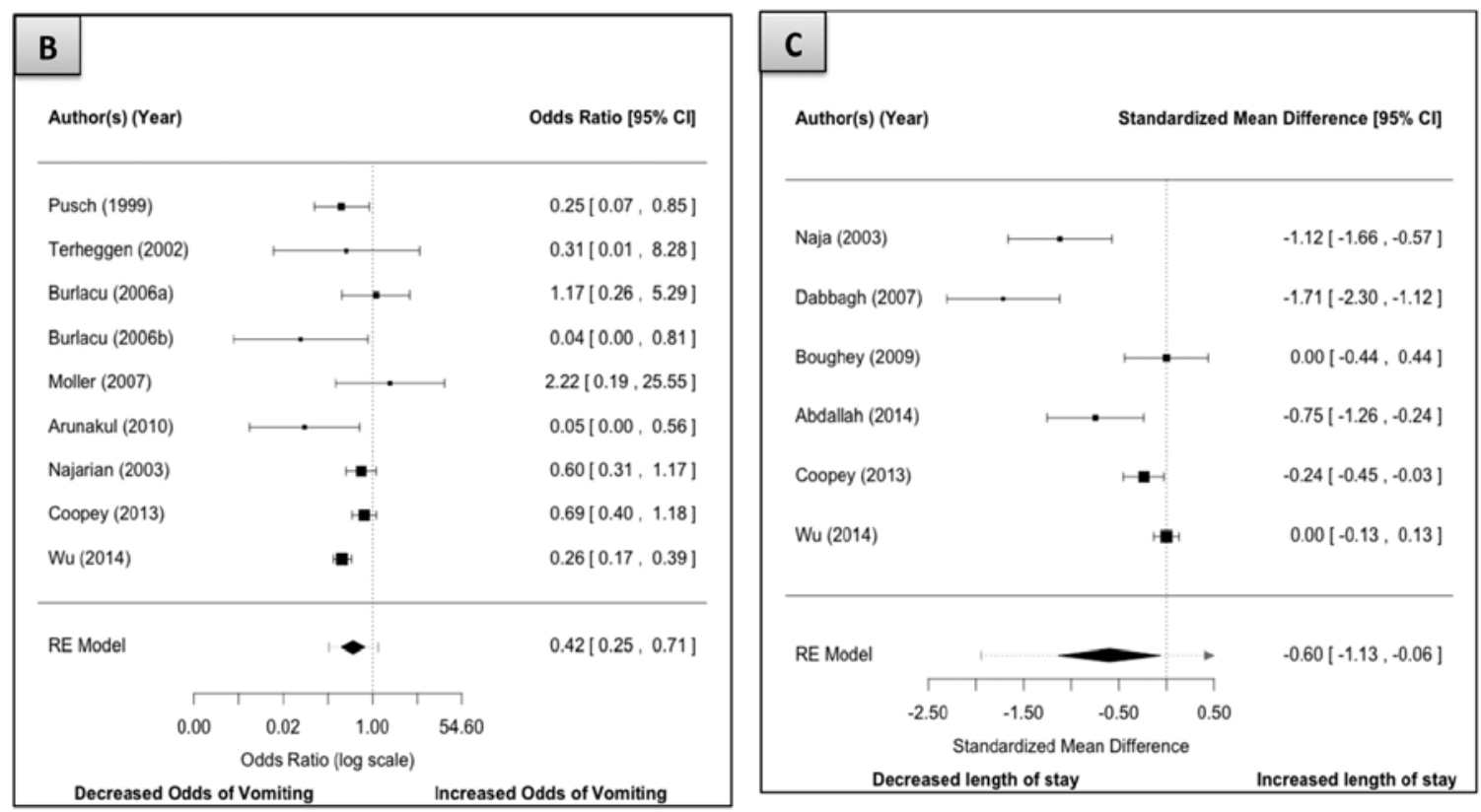

Fig. 5. Forest plots for secondary outcomes. (A) Nausea: thoracic paravertebral block reduced the incidence of postoperative nausea, as assessed by random-effects modeling. (B) Vomiting: thoracic paravertebral block reduced the incidence of postoperative vomiting, as assessed by random-effects modeling. (C) Thoracic paravertebral block is associated with statistically significant reduction of the length of hospital stay, as assessed by random-effects modeling. 


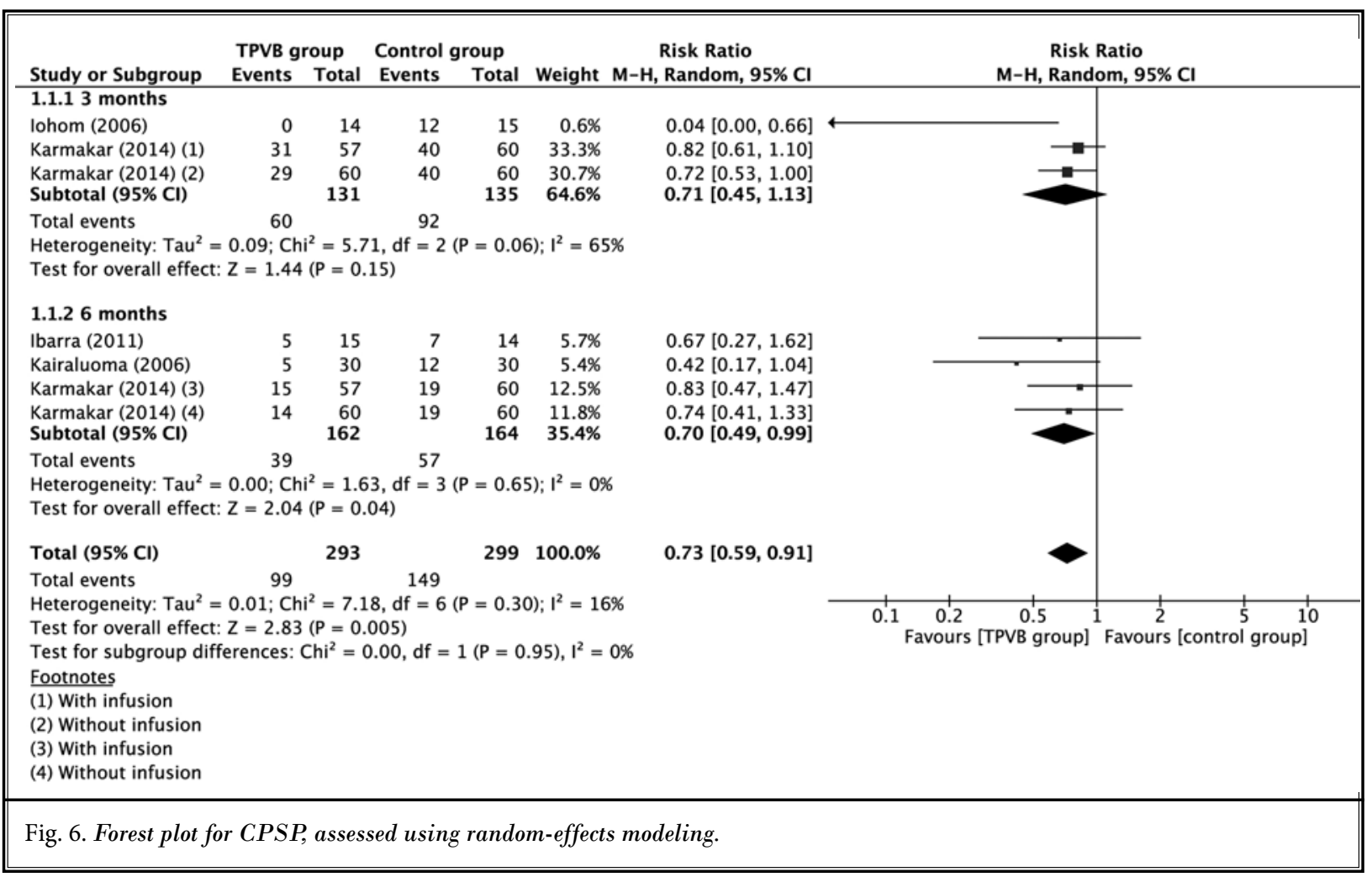

Table 4. Reported thoracic paravertebral block complications in breast surgery.

\begin{tabular}{|c|c|c|c|c|c|c|c|}
\hline \multirow[t]{2}{*}{ Complication } & \multirow{2}{*}{ Total } & \multicolumn{3}{|c|}{ Anatomical vs ultrasound } & \multicolumn{3}{|c|}{ Single vs multiple levels } \\
\hline & & Anatomical & Ultrasound & $P$-value* & Single & Multiple & $P$-value* \\
\hline $\begin{array}{l}\text { Failure** }^{* *} \\
(9,26,28-30,33,34,36,39,41,44,45,49-51,53-56)\end{array}$ & $\begin{array}{c}5.6 \% \\
64(1255) \\
\end{array}$ & $\begin{array}{c}5.6 \% \\
50(992) \\
\end{array}$ & $\begin{array}{c}5.3 \% \\
14(263) \\
\end{array}$ & 0.985 & $\begin{array}{c}3.4 \% \\
20(583) \\
\end{array}$ & $\begin{array}{c}7.7 \% \\
44(672) \\
\end{array}$ & 0.024 \\
\hline $\begin{array}{l}\text { Hypotension/Epidural } \\
\text { spread }(9,24,25,27- \\
29,33,34,36,37,39,41,44,45,49-51,53-56)\end{array}$ & $\begin{array}{c}2.1 \% \\
35(1639)\end{array}$ & $\begin{array}{c}2.5 \% \\
35(1376)\end{array}$ & $\begin{array}{c}0 \% \\
0(263)\end{array}$ & 0.003 & $\begin{array}{c}1.9 \% \\
12(632)\end{array}$ & $\begin{array}{c}2.3 \% \\
23(1007)\end{array}$ & 0.734 \\
\hline $\begin{array}{l}\text { Horner's syndrome } \\
(9,25,26,28,29,33,34,36,37,39,41,44,45,49,51,53- \\
56)\end{array}$ & $\begin{array}{c}1.8 \% \\
22(1342)\end{array}$ & $\begin{array}{c}2.2 \% \\
22(1079)\end{array}$ & $\begin{array}{c}0 \% \\
0(263)\end{array}$ & 0.012 & $\begin{array}{c}1.5 \% \\
9(617)\end{array}$ & $\begin{array}{c}2 \% \\
12(725)\end{array}$ & 0.949 \\
\hline $\begin{array}{l}\text { Vascular puncture } \\
(9,25,26,28,29,33,34,36,39,41,44,45,49,51,53-56)\end{array}$ & $\begin{array}{c}0.5 \% \\
6(1164) \\
\end{array}$ & $\begin{array}{c}0.6 \% \\
6(901) \\
\end{array}$ & $\begin{array}{c}0 \% \\
0(263) \\
\end{array}$ & 0.347 & $\begin{array}{c}0 \% \\
0(617) \\
\end{array}$ & $\begin{array}{c}1 \% \\
6(547) \\
\end{array}$ & 0.010 \\
\hline $\begin{array}{l}\text { Epinephrine } \\
\text { absorption }(9,25,28,39,41,49-51,55-57)\end{array}$ & $\begin{array}{c}0.3 \% \\
2(842) \\
\end{array}$ & $\begin{array}{c}0.4 \% \\
2(612) \\
\end{array}$ & $\begin{array}{c}0 \% \\
0(230) \\
\end{array}$ & 1 & $\begin{array}{c}0.2 \% \\
1(403) \\
\end{array}$ & $\begin{array}{c}0.3 \% \\
1(439) \\
\end{array}$ & 1 \\
\hline $\begin{array}{l}\text { Convulsions } \\
(9,28,29,33,34,36,39-41,44,45,51,53-56) \\
\end{array}$ & $\begin{array}{c}0.2 \% \\
2(954) \\
\end{array}$ & $\begin{array}{c}0.3 \% \\
2(691) \\
\end{array}$ & $\begin{array}{c}0 \% \\
0(263) \\
\end{array}$ & 1 & $\begin{array}{c}0.3 \% \\
2(593) \\
\end{array}$ & $\begin{array}{c}0 \% \\
0(361) \\
\end{array}$ & 1 \\
\hline $\begin{array}{l}\text { Pneumothorax } \\
(9,24-26,28,29,33,34,36,37,39-41,44,45,49-57)\end{array}$ & $\begin{array}{c}0.1 \% \\
2(1945)\end{array}$ & $\begin{array}{c}0.1 \% \\
2(1450)\end{array}$ & $\begin{array}{c}0 \% \\
0(495)\end{array}$ & 1 & $\begin{array}{c}0 \% \\
0(637)\end{array}$ & $\begin{array}{c}0.1 \% \\
2(1308)\end{array}$ & 1 \\
\hline $\begin{array}{l}\text { Hemothorax } \\
(9,25,26,28,29,33,34,36,37,39,41,44,45,49,51-57)\end{array}$ & $\begin{array}{c}0 \% \\
0(1613)\end{array}$ & $\begin{array}{c}0 \% \\
0(1118)\end{array}$ & $\begin{array}{c}0 \% \\
0(495)\end{array}$ & 1 & $\begin{array}{c}0 \% \\
0(617)\end{array}$ & $\begin{array}{c}0 \% \\
0(996)\end{array}$ & 1 \\
\hline $\begin{array}{l}\text { Nerve damage } \\
(9,25,26,28,29,33,34,36,39,41,44,45,49,51,53-56)\end{array}$ & $\begin{array}{c}0 \% \\
0(1164)\end{array}$ & $\begin{array}{c}0 \% \\
0(901)\end{array}$ & $\begin{array}{c}0 \% \\
0(263)\end{array}$ & 1 & $\begin{array}{c}0 \% \\
0(617)\end{array}$ & $\begin{array}{c}0 \% \\
0(547)\end{array}$ & 1 \\
\hline
\end{tabular}

${ }^{*} P$-value calculated by Chi-square and Fisher exact tests, as applicable.

${ }^{\star *}$ Failure: whenever authors mentioned block failure or that the procedure converted to general anesthesia while it was planned to be under sedation because the patient cannot tolerate pain. 
continuous infusions. Paravertebral blocks had a limited effect on intraoperative and postoperative opioid consumption during the initial 24 postoperative hours, and reduced nausea and vomiting. However, blocks had no clinically important effect on the duration of hospitalization. TPVB may also have reduced the incidence of chronic postsurgical pain 6 months after breast surgery, but evidence is limited.

A previous meta-analysis noted that adding fentanyl to epidural local anesthetics reduced pain (58). Our results were similar: the addition of fentanyl to the local anesthetic was associated with less acute postoperative pain at rest in the first 24,48 , and 72 hours. The addition of fentanyl to the mixture also decreased pain during movement in the first 24 and 72 hours. These results are probably related to the systemic absorption (through the highly vascular paravertebral space) of the highly lipophilic drug fentanyl (59) resulting in serum concentrations essentially equivalent to those identified with the IV use of fentanyl.

Most investigators performed single level blocks $(9,24,25,27,29-31,33,35,38-40,42,43,46)$, although others performed multi-level blocks $(24,26,28,34,36,37,41,45)$. Investigators performing single-level blocks suggest that the injected drug spreads 4 or 5 thoracic dermatomes, thus providing an adequate block with less risk of complications (60). However, there is no published data comparing the 2 techniques. In our study, the use of a single versus a multi-injection technique did not affect the efficacy of paravertebral block for acute postoperative pain at rest. However, when examining pain at movement, multi-level blocks were associated with better analgesia during the initial 2, 48, and 72 hours.

The paravertebral space spans the vertebral column and is continuous with the epidural space medially and the intercostal space laterally. Because local anesthetics spread cranially and caudally when injected in the paravertebral space, the spread depends on the level of the injection, anatomic variance amongst patients, and the volume of injected local anesthetic. Unsurprisingly, radiologic studies demonstrate that single-injection paravertebral blocks result in inconsistent spread of anesthetic and that multi-injection techniques likely produce a wider and more effective block (61). While there was no significant difference in pain for patients at rest with single or multiple techniques, it is possible that with movement and more severe pain, the improved spread of the anesthetics led to significant pain reduction.

Placing an indwelling paravertebral catheter at one or multiple levels allows for continued infusion of local anesthetics and a prolonged block. In our analysis, the use of single injection versus continuous catheter technique did not have a statistical significance in the efficacy of the block for acute postoperative pain. Luyet et al (62) used contrast dye injection and fluoroscopic examination to determine the location of landmarkplaced thoracic paravertebral catheters in 31 patients. They further assessed the correlation between the sensory blocks produced after local anesthetic injection through the catheter with the distribution of contrast dye. In 9 patients (29\%), the contrast dye did not spread within the paravertebral space as intended. These misplaced catheters were found in to be in the erector spinae musculature $(n=5)$, epidural space $(n=3)$, or pleural space $(n=1)$. Even in the $21(70 \%)$ patients with well-positioned catheters, only 17 (57\%) provided good analgesia. It thus appears that paravertebral catheters are often poorly positioned with consequent inadequate analgesia or even if in the appropriate place, may not always prove effective. Although catheter positioning is presumably improved by ultrasound guidance, studies are lacking.

One of the important findings in this meta-analysis is that TPVB might have the potential to reduce the incidence of persistent pain after breast surgery. Numerous studies demonstrate strong associations between acute pain (and catastrophizing) and subsequent development of persistent incisional pain $(63,64)$. These observations suggest that better control of acute pain may reduce the risk of persistent pain. Our results are consistent with this theory in that paravertebral blocks, which reduced postoperative pain levels, also reduced persistent pain - suggesting a causal relationship that could not reliably be concluded from previous nonrandomized cohort studies. Available evidence thus suggests that effective perioperative analgesia may provide long-term benefit - but the quantity of available evidence remains severely limited.

There is increasing evidence that ultrasound guidance of peripheral nerve blocks decreases the amount of local anesthetic required, improves success rates, decreases time to block onset, and reduces complications such as local anesthetic systemic toxicity (65). However, we did not find that the use of ultrasound-guided TPVB improves its efficacy. Furthermore, procedures were equally likely to succeed when ultrasound was used. Of note, all reported block failures that we found with ultrasound guidance occurred a single retrospective study (51). The same study reported that multiple-level 
blocks were associated with slightly more complications, mostly vascular puncture and procedure failure. None of the vascular punctures occurred in studies of ultrasound-guided blocks.

The incidence of complications and the variables leading to these complications provides important information on block techniques and safety outcomes. We found that ultrasound guidance was associated with fewer complications, specifically hypotension/ epidural spread and Horner's syndrome. This could be explained by needle visualization and the ability to visualize the spread of local anesthetics in the appropriate and intended location. We were unable to determine if vascular puncture was reduced in patients having ultrasound-guided blocks because none of the vascular punctures were in studies of ultrasound-guided blocks. But ultrasound may nonetheless reduce minor complications (e.g., Horner's syndrome). Furthermore, the incidence of vascular puncture was increased with multi-injection techniques, presumably because more frequent needle sticks provided additional opportunity for inadvertent contact with vascular structures. In the hands of inexperienced anesthesiologists, block quality might vary. However, the procedure is usually allocated to skilled and experienced clinicians in the context of a study. Consistent with this theory, the success rate was high and there were remarkably few reported complications.

With 24 studies, this meta-analysis included the largest number of RCTs to date, representing 11 more than Schnabel et al (7) and 19 more than Tahiri et al (8). Our study thus provides a comprehensive evaluation of the effect of thoracic paravertebral blocks across diverse studies. Many countries were represented, suggesting that our results are generalizable.

\section{Limitations}

Despite our attempts to include as many eligible studies as possible, the number of studies available was limited for several of our meta-analytic models. For example, 6 studies provided information on postoperative pain at 48 and 72 hours, 6 evaluated the length of hospital stay, and 4 reported incidences of CPSP. As such, it is premature to draw conclusions regarding the effect of TPVB on these specific outcomes based on the current findings, and caution is warranted when interpreting these results.

Our primary meta-analysis evaluated randomized outcomes assessed in the underlying RCTs. These within-study comparisons, such as pain scores and opioid consumption, are thus well protected again selection bias, confounding, and measurement bias - the major sources of error in clinical research. Our meta-analysis of such factors thus remains well protected from these sources of error (although not against publication bias).

However, we also make comparisons across studies of non-randomized factors. For example, we compare across studies on type of local anesthetic or the use of ultrasound guidance. These nonrandomized comparisons are essentially cohort studies and thus poorly protected against confounding and center effects. Furthermore, the comparisons were across various sites and over a substantial period of time; the potential for center and time-dependent effects is thus substantial. Unlike the randomized interventions, results based on other interventions should be considered associations rather than causal, and largely exploratory.

For the procedure complications analysis, we included any study that commented on the complication. However, these results are less robust than others since some of the data were from nonrandomized cohort studies. Confounding factors (e.g., patients' characteristics) may be present and we did not have access to the raw data from these studies that might have allowed statistical adjustment for known confounding factors. Because local anesthetic doses were not consistently reported in many studies, we were unable to specifically attribute observed differences in effect among various local anesthetics to difference in dosing.

Asymmetric funnel plots were found in our metaanalytic models for acute pain at rest (first 2 hours, first 24 hours, and first 48 hours), acute pain at movement (first 72 hours), and morphine consumption (first 2 hours). There is thus potential for publication bias in the pooled estimates. We recommend caution when interpreting results from these models.

All studies included in our analysis used placebo control groups. This is an appropriate scientific approach, but differences between the block and controls groups would likely have been even smaller had the control groups been given multimodal analgesia.

\section{Conclusion}

In conclusion, results from our analyses showed that, compared with placebo control, the use of TPVB in breast surgery improves analgesia for up to 72 postoperative hours at rest and during movement, and reduces nausea and vomiting. Table 5 summarized our recommended techniques to improve the efficacy and safety of the block based on findings from our analyses. 
Table 5. Summary of the best available TPVB techniques.

\begin{tabular}{|l|l|}
\hline Recommended technique* & Available evidence from our meta-analysis \\
\hline Adding fentanyl & $\begin{array}{l}\text { Improves pain control at rest (first 24, 38, and } 72 \text { hours) and movement (first 24 and } 72 \text { hours), without } \\
\text { increasing the risk of nausea or vomiting. }\end{array}$ \\
\hline Multiple levels block & $\begin{array}{l}\text { Improves pain control only with movement at the first 2, 48, and } 72 \text { hours. However, this may increase } \\
\text { the risk of procedure complications (e.g., inadvertent vascular puncture). }\end{array}$ \\
\hline Ultrasound-guidance & Did not show any evidence of improving the block efficacy, however, it does for safety. \\
\hline
\end{tabular}

${ }^{\star}$ Technique was only recommended if significant effects were found at more than one analysis point (e.g., improve pain scores at more than one time point).

\section{Author Contributions:}

All authors had full access to all the data in the study and take responsibility for the integrity of the data and the accuracy of the data analysis.

Dr. Abdullah S. Terkawi: study design, data extraction, statistical analysis, and writing the manuscript, Dr.. Siny Tsang: statistical analysis and writing the manuscript, Dr. Daniel I. Sessler: study design and writing the manuscript, Dr. Rayan S. Terkawi: data extraction, Mrs. Megan S. Nunemaker: databases search, Dr. Marcel E. Durieux: writing the manuscript, and Dr. Ashley Shilling: data extraction and writing the manuscript.

\section{Conflict of Interest}

The authors declare no conflict of interest. The study was not funded.

\section{Acknowledgment}

We thank Lucas Fernandez, M.D, Mikhail Galperin, M.D, and Zhiyi Zuo, M.D, from the department of Anesthesiology, University of Virginia, Charlottesville, VA, for their help in reviewing and extracting data from the Spanish, Russian, and Japanese articles. We also thank Edward Mascha, Ph.D, and the rest of the authors of Wu et al study in providing us unpublished data and clarifying our queries. 
Appendix: Forest plots for the main effects of thoracic paravertebral blocks on postoperative pain and opioid consumptions, using the random effects models.

\section{Pain scores at rest at the first 2 hours.} Author(s) and Year

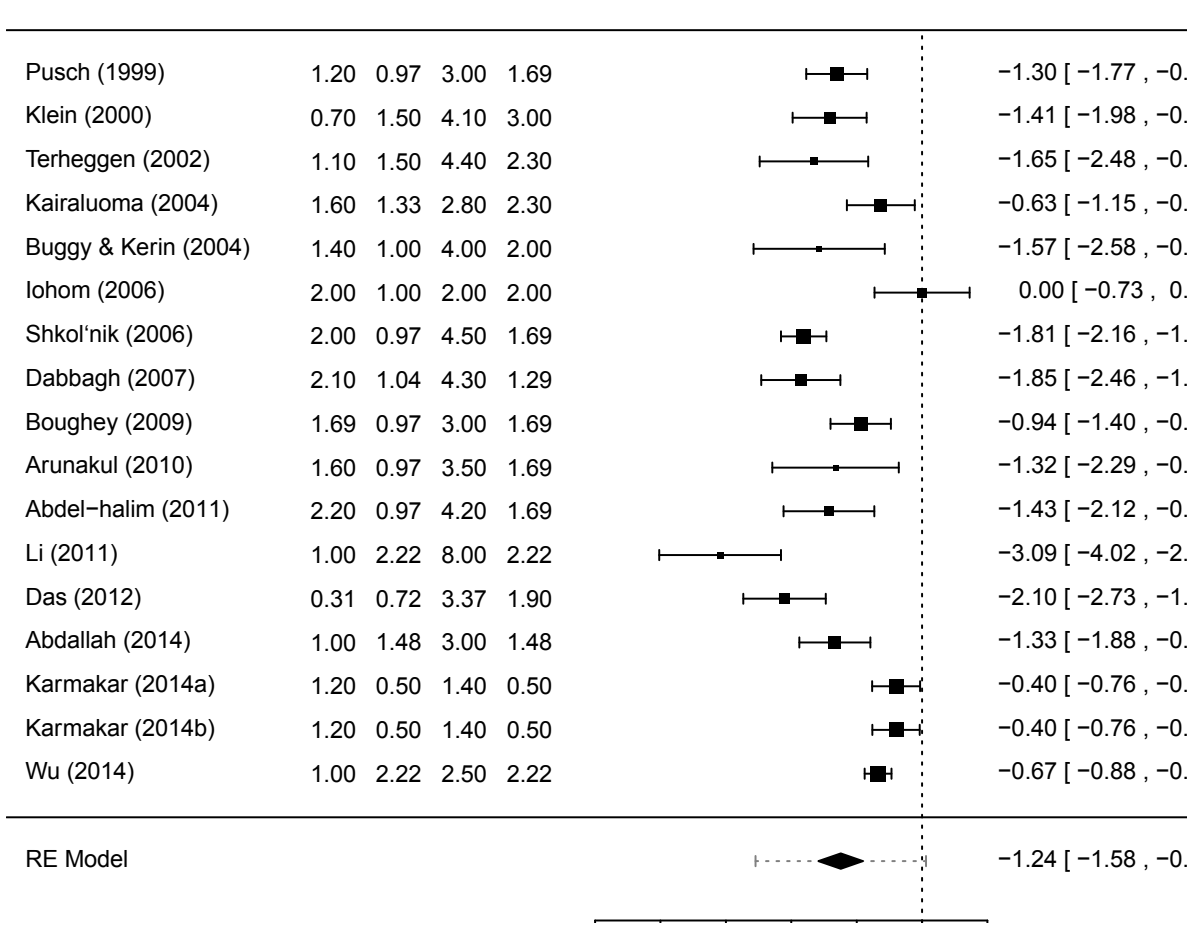

\section{Pain scores at rest at the first 24 hours.}

\begin{tabular}{|c|c|c|c|c|c|c|}
\hline \multirow{3}{*}{$\begin{array}{l}\text { Author(s) and Year } \\
\text { Pusch (1999) }\end{array}$} & \multicolumn{4}{|c|}{ Experimental Control } & \multirow{2}{*}{\multicolumn{2}{|c|}{ Standardized Mean Difference $[95 \% \mathrm{Cl}]$}} \\
\hline & Mean & SD & Mean & SD & & \\
\hline & 1.30 & 1.41 & 2.90 & 1.29 & $\mapsto$ & $-1.17[-1.63,-0.71]$ \\
\hline Klein $(2000)$ & 2.80 & 2.50 & 4.00 & 2.50 & $\longmapsto$ & $-0.47[-0.99,0.04]$ \\
\hline Naja (2003) & 1.70 & 1.41 & 6.20 & 1.29 & $\longmapsto$ & $-3.28[-4.05,-2.50]$ \\
\hline Kairaluoma (2004) & 0.60 & 0.96 & 1.20 & 1.56 & $\longmapsto$ & $-0.46[-0.97,0.05]$ \\
\hline Buggy \& Kerin (2004) & 2.00 & 2.00 & 4.10 & 1.00 & $\longmapsto \longrightarrow$ & $-1.27[-2.23,-0.31]$ \\
\hline lohom (2006) & 1.00 & 1.00 & 1.00 & 1.00 & $\longmapsto$ & $0.00[-0.73,0.73]$ \\
\hline Shkol'nik (2006) & 1.20 & 1.41 & 3.00 & 1.29 & $\begin{array}{l}H \\
H\end{array}$ & $-1.32[-1.65,-1.00]$ \\
\hline Boughey (2009) & 3.76 & 1.41 & 4.24 & 1.29 & $\mapsto$ & $-0.35[-0.79,0.09]$ \\
\hline Arunakul (2010) & 2.60 & 1.41 & 2.00 & 1.29 & $\longmapsto$ & $\longrightarrow 0.42[-0.46,1.31]$ \\
\hline Buckenmaier (2010a) & 2.70 & 2.50 & 2.80 & 2.20 & $\longmapsto$ & $-0.04[-0.62,0.53]$ \\
\hline Buckenmaier (2010b) & 2.50 & 1.80 & 2.80 & 2.20 & $\longmapsto$ & $-0.15[-0.72,0.43]$ \\
\hline Abdel-halim (2011) & 1.50 & 1.41 & 2.50 & 1.29 & $\longmapsto$ & $-0.72[-1.36,-0.08]$ \\
\hline $\mathrm{Li}(2011)$ & 1.00 & 0.74 & 2.00 & 1.48 & $\longmapsto \vdots$ & $-0.78[-1.44,-0.12]$ \\
\hline Bhuvaneswari (2012a) & 3.50 & 2.96 & 6.00 & 1.48 & $\longmapsto$ & $-1.03[-1.88,-0.18]$ \\
\hline Bhuvaneswari (2012b) & 0.00 & 2.22 & 6.00 & 1.48 & & $-3.07[-4.25,-1.89]$ \\
\hline Bhuvaneswari (2012c) & 0.00 & 2.22 & 6.00 & 1.48 & & $-3.07[-4.25,-1.89]$ \\
\hline Das (2012) & 2.58 & 0.50 & 2.73 & 0.45 & $\mapsto-1$ & $-0.31[-0.82,0.20]$ \\
\hline Abdallah (2014) & 1.00 & 1.48 & 3.00 & 1.48 & $\longmapsto$ & $-1.33[-1.88,-0.79]$ \\
\hline Ilfeld (2014) & 2.00 & 2.22 & 4.00 & 2.96 & $\longmapsto-1$ & $-0.75[-1.28,-0.23]$ \\
\hline Karmakar (2014a) & 1.55 & 0.50 & 1.50 & 0.50 & $\stackrel{1}{-1}$ & $0.10[-0.26,0.46]$ \\
\hline Karmakar (2014b) & 1.06 & 0.50 & 1.50 & 0.50 & $\mapsto-1 \quad \vdots$ & $-0.87[-1.25,-0.50]$ \\
\hline RE Model & & & & & & $-0.89[-1.29,-0.49]$ \\
\hline
\end{tabular}


Pain scores at rest at the first 48 hours.

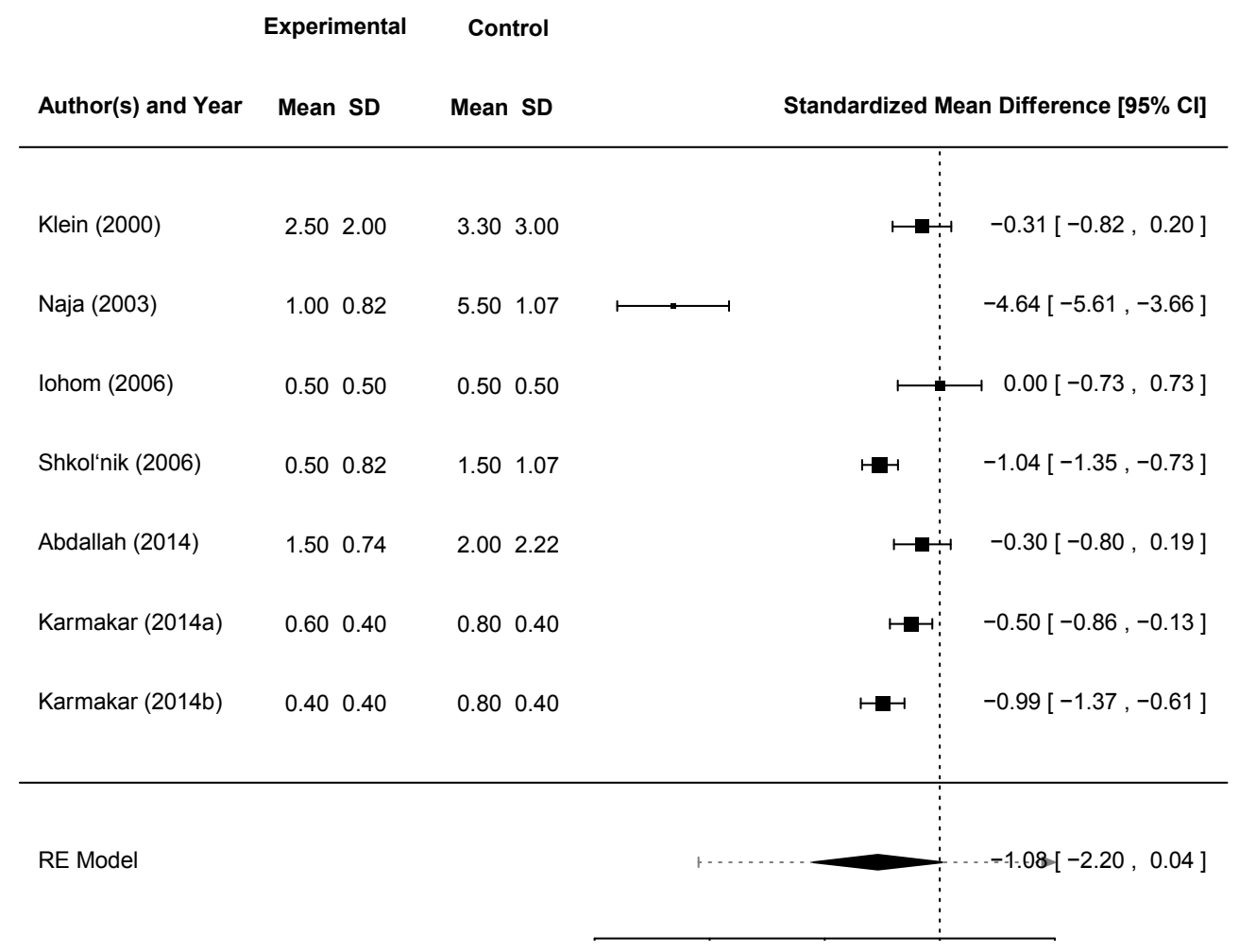

\section{Pain scores at rest at the first 72 hours.}

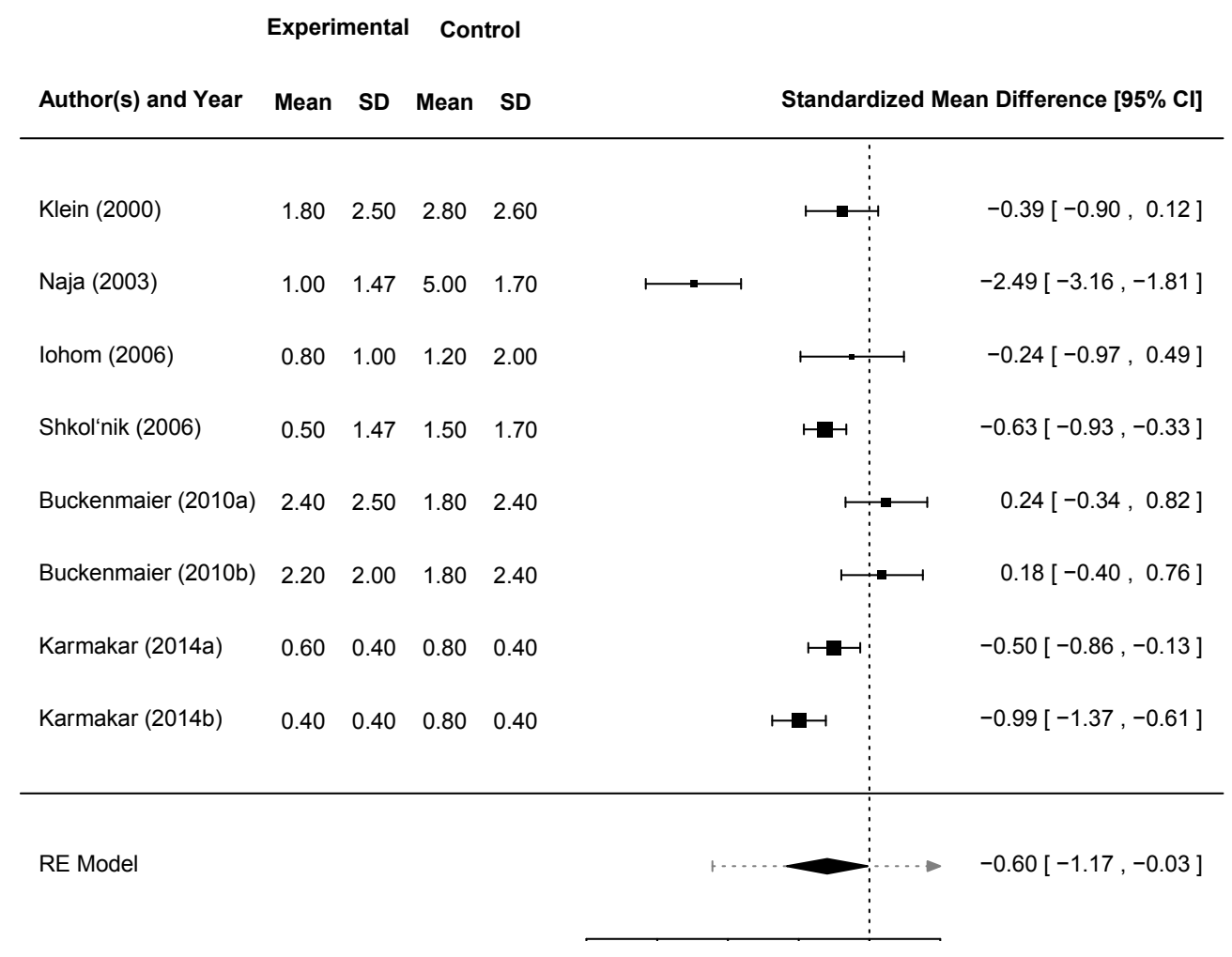


Pain scores at movements at the first 2 hours.

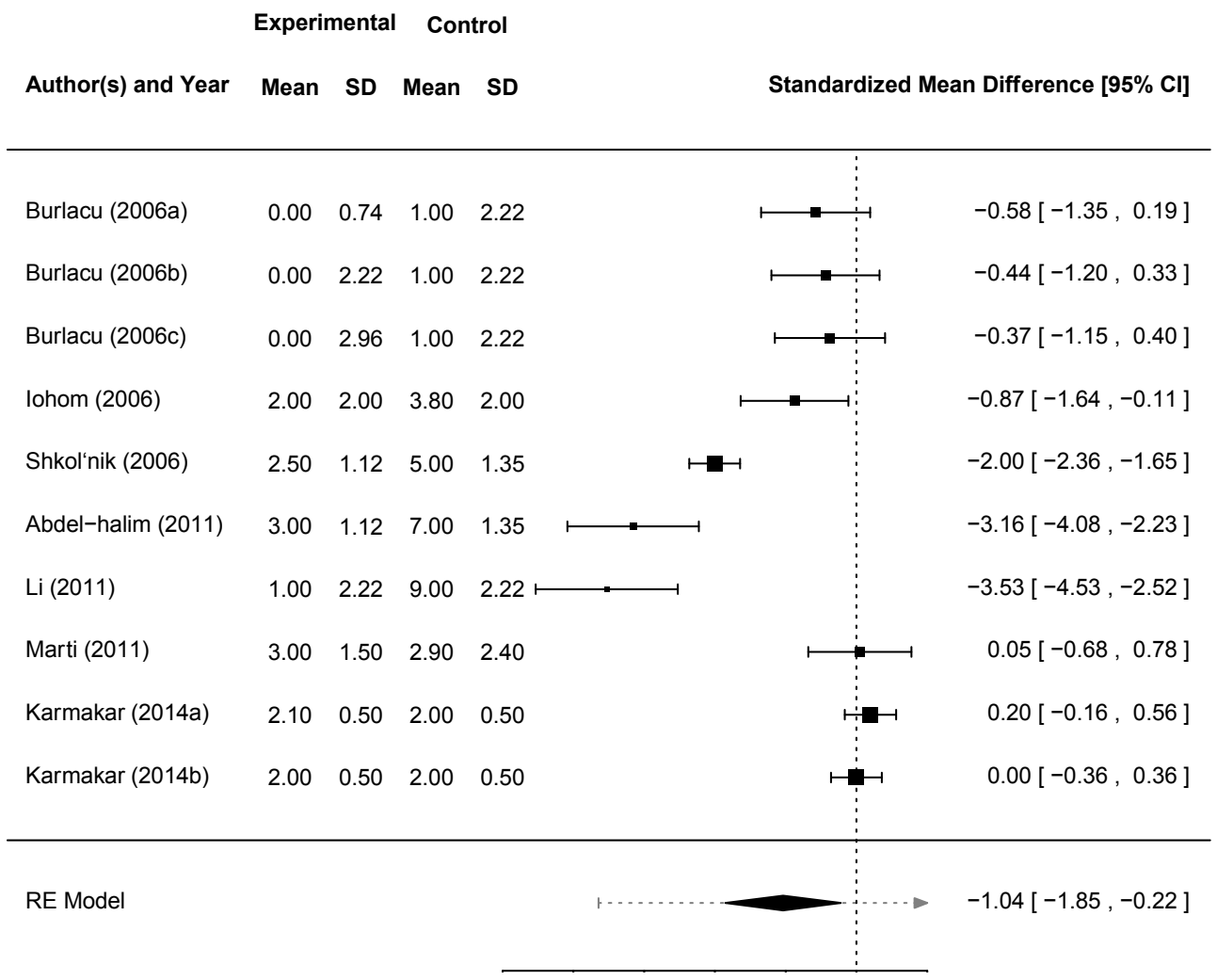

Pain scores at movement at the first 24 hours.

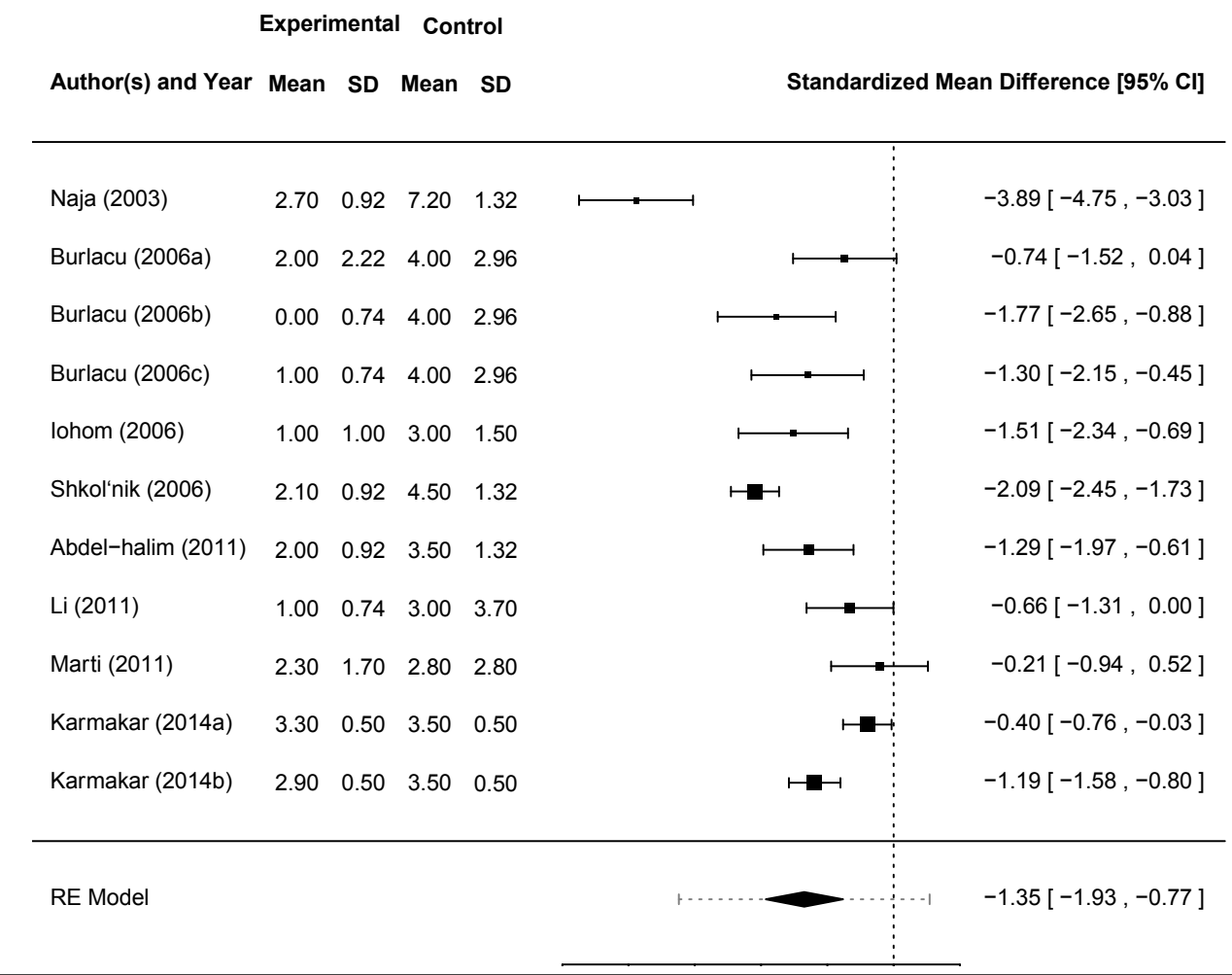




\section{Pain scores at movements at the first 48 hours.}

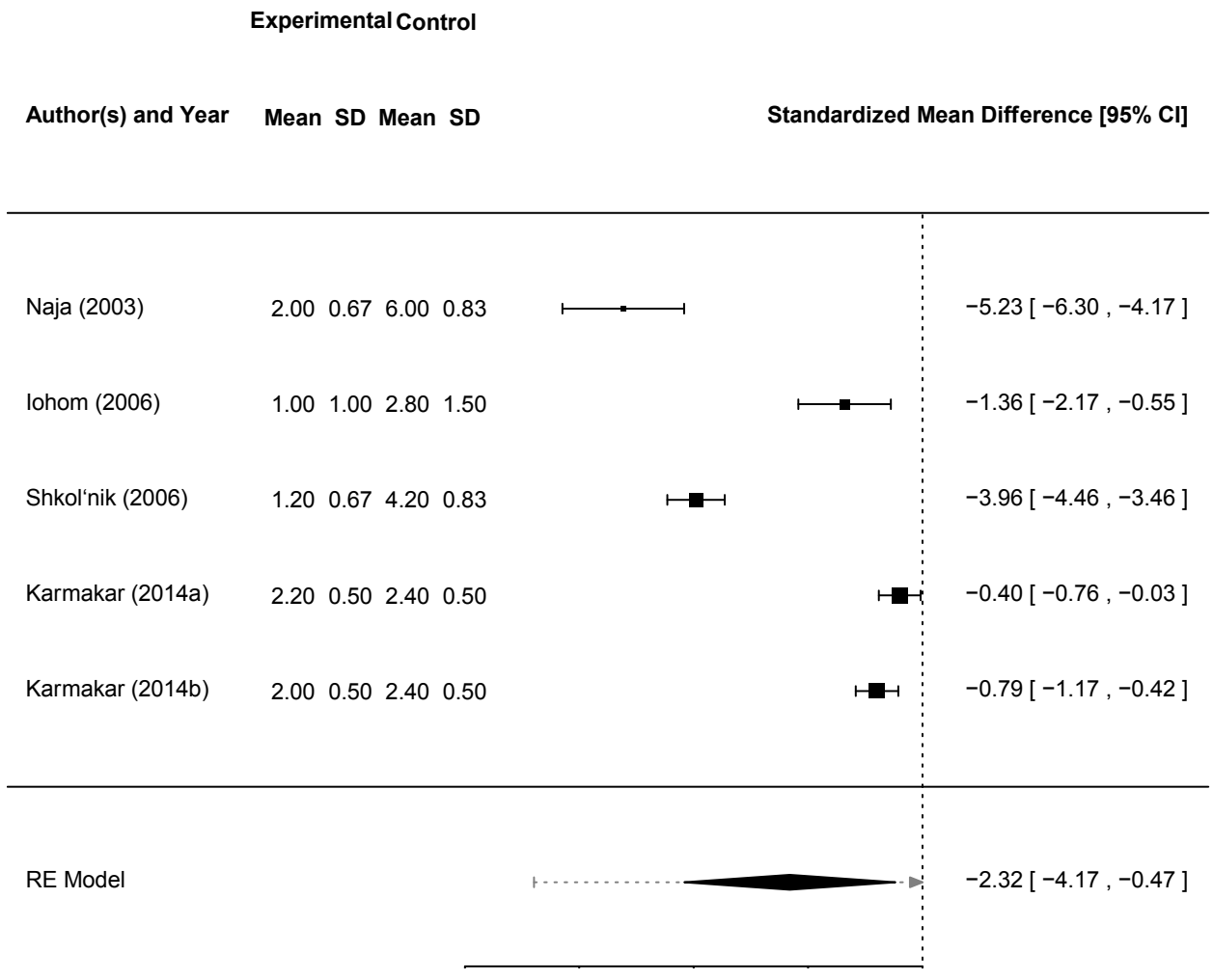

Pain scores at movements at the first 72 hours.

Author(s) and Year Mean SD Mean SD

Standardized Mean Difference $[95 \% \mathrm{Cl}]$

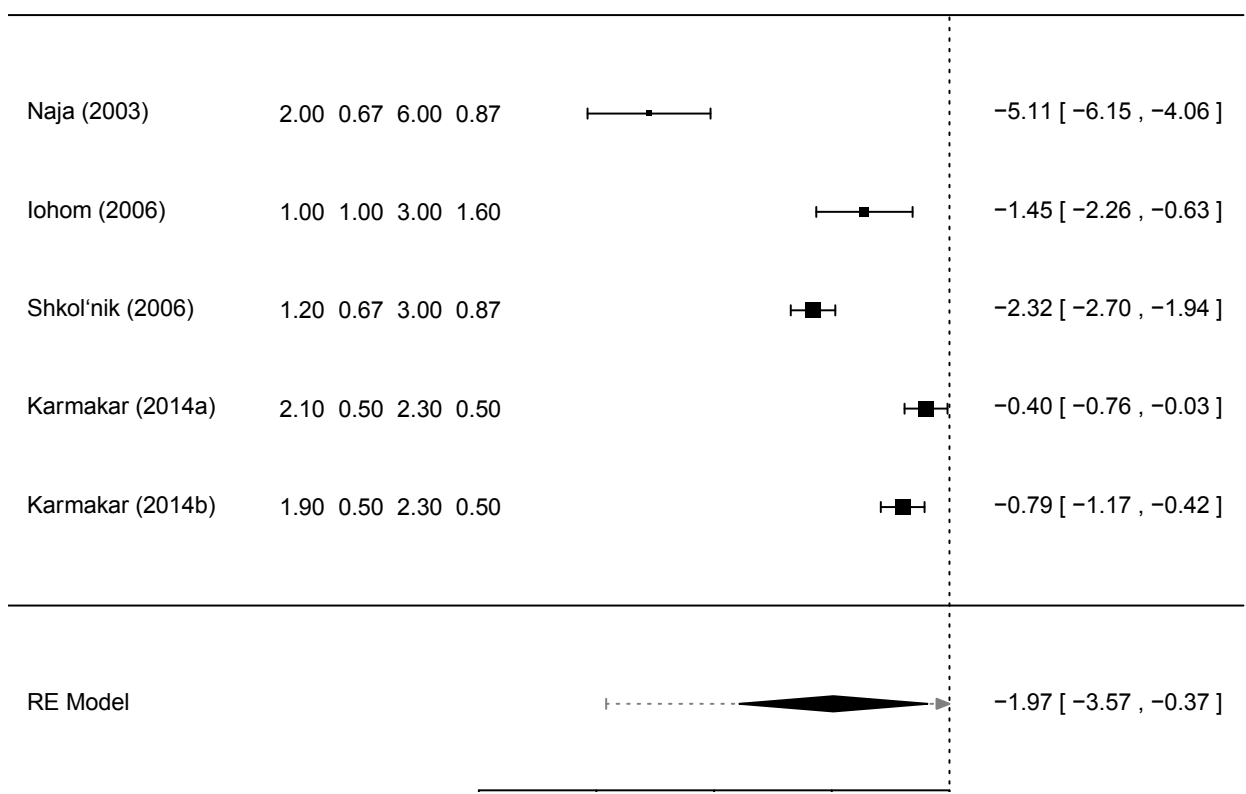


Intraoperative opioid (morphine equivalent) consumption (in $\mathbf{m g}$ ).

\begin{tabular}{|c|c|c|c|c|c|c|}
\hline \multirow{3}{*}{$\begin{array}{l}\text { Author(s) (Year) } \\
\text { Klein (2000) }\end{array}$} & \multicolumn{4}{|c|}{ Experimental Control } & \multirow{2}{*}{\multicolumn{2}{|c|}{ Standardized Mean Difference $[95 \% \mathrm{Cl}]$}} \\
\hline & Mean & SD & Mean & SD & & \\
\hline & 28.00 & 12.00 & 23.50 & 10.00 & $\longmapsto$ & $0.40[-0.11,0.91]$ \\
\hline Kairaluoma (2004) & 21.70 & 9.00 & 25.00 & 8.00 & $\longmapsto$ & $-0.38[-0.89,0.13]$ \\
\hline Burlacu (2006a) & 5.00 & 6.00 & 11.90 & 6.50 & $\longmapsto \longmapsto \vdots$ & $-1.07[-1.87,-0.26]$ \\
\hline Burlacu (2006b) & 6.00 & 4.73 & 11.90 & 6.50 & $\longmapsto-$ & $-1.00[-1.80,-0.20]$ \\
\hline Burlacu (2006c) & 8.00 & 3.00 & 11.90 & 6.50 & $\longmapsto \quad \vdots$ & $-0.73[-1.52,0.07]$ \\
\hline Moller (2007) & 20.00 & 11.11 & 35.00 & 7.41 & $\longmapsto$ & $-1.58[-2.09,-1.08]$ \\
\hline Arunakul (2010) & 3.70 & 2.97 & 11.65 & 5.44 & $\longmapsto$ & $-1.74[-2.77,-0.71]$ \\
\hline Abdel-halim (2011) & 13.20 & 4.70 & 19.30 & 3.90 & $\longmapsto$ & $-1.38[-2.07,-0.69]$ \\
\hline Das (2012) & 10.77 & 1.17 & 15.08 & 2.66 & $\longmapsto$ & $-2.07[-2.70,-1.44]$ \\
\hline Abdallah (2014) & 1.70 & 3.00 & 15.90 & 7.80 & $\longmapsto$ & $-2.40[-3.05,-1.76]$ \\
\hline Ilfeld (2014) & 3.00 & 1.48 & 2.50 & 1.85 & $\stackrel{\vdots}{\vdots}$ & $0.29[-0.21,0.80]$ \\
\hline Karmakar (2014a) & 0.00 & 0.74 & 1.50 & 2.22 & $\mapsto-1$ & $-0.89[-1.27,-0.51]$ \\
\hline Karmakar (2014b) & 0.00 & 0.74 & 1.50 & 2.22 & $\mapsto$ & $-0.90[-1.28,-0.52]$ \\
\hline Wu (2014) & 5.00 & 9.26 & 20.00 & 14.81 & $\mathrm{HH}$ & $-1.20[-1.42,-0.99]$ \\
\hline RE Model & & & & & & $-1.03[-1.45,-0.60]$ \\
\hline
\end{tabular}

Opioid consumptions in (in $\mathrm{mg}$ ) the first 2 hours postoperatively.

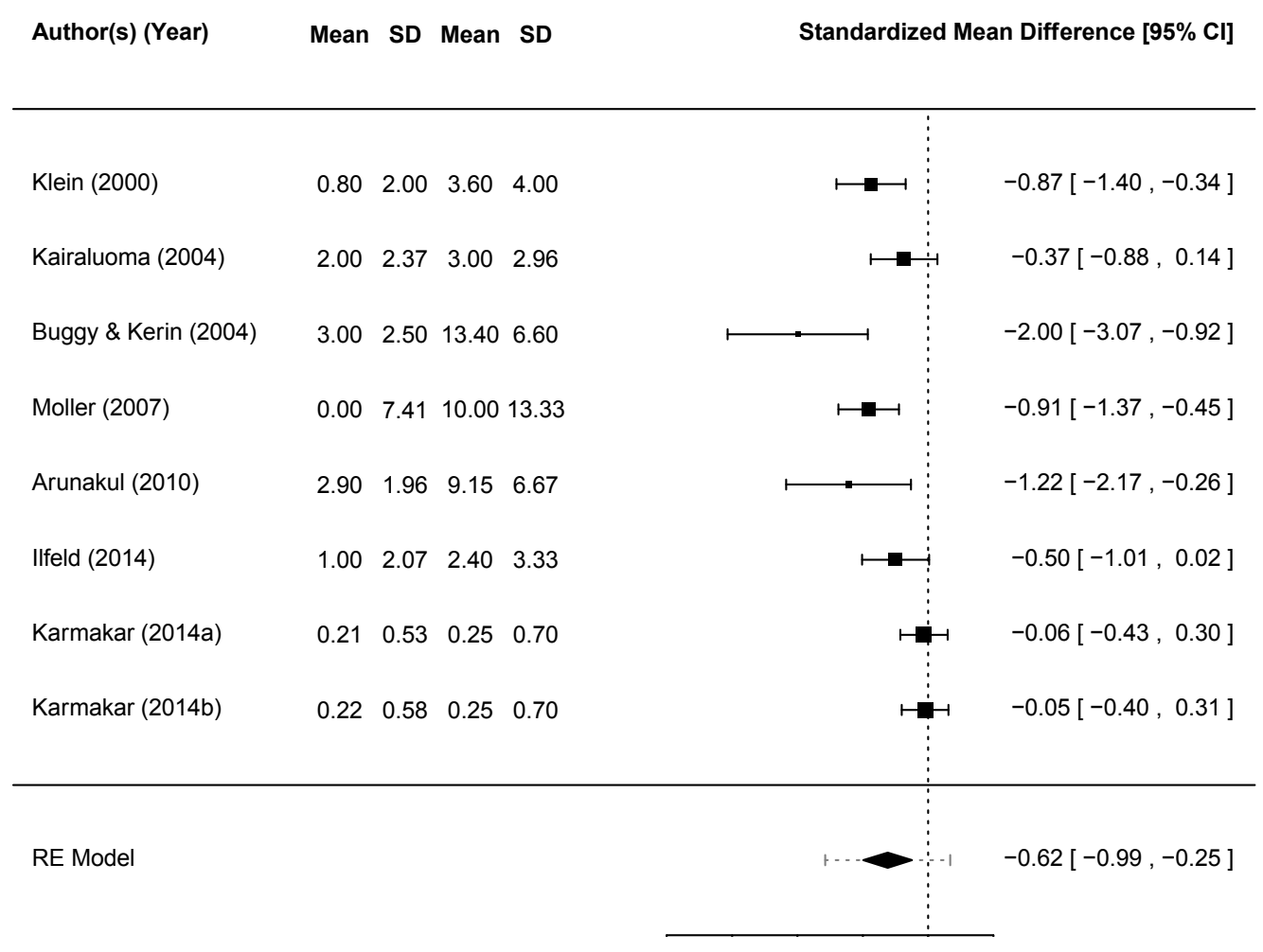




\section{Opioid consumptions (in $\mathrm{mg}$ ) in the first 24 hours postoperatively.}

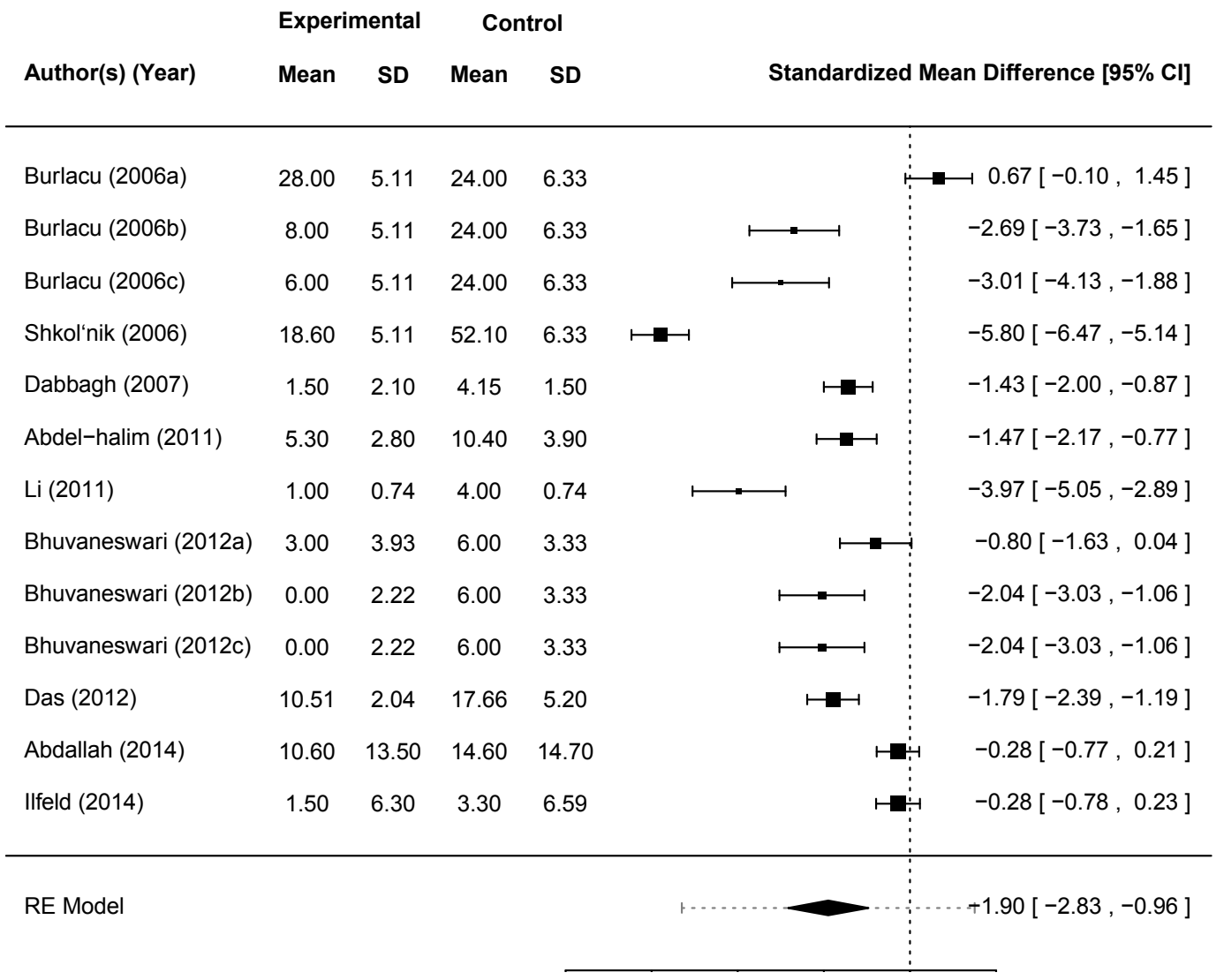

\section{References}

1. National Cancer Institute. Breast Cancer Treatment. 2015. Available at: www. cancer.gov/cancertopics/pdq/treatment/ breast/healthprofessional accessed in March 21, 2015.

2. Senkus E, Kyriakides S, Penault-Llorca F, Poortmans P, Thompson A, Zackrisson S, Cardoso F; ESMO Guidelines Working Group. Primary breast cancer: ESMO Clinical Practice Guidelines for diagnosis, treatment and follow-up. Ann Oncol 2013; 24:vi7-23.

3. Benhamou D, Berti M, Brodner G, De Andres J, Draisci G, Moreno-Azcoita M, Neugebauer EA, Schwenk W, Torres LM, Viel E. Postoperative Analgesic THerapy Observational Survey (PATHOS): A practice pattern study in 7 central/ southern European countries. Pain 2008; 136:134-141.

4. Correll DJ, Vlassakov KV, Kissin I. No evidence of real progress in treatment of acute pain, 1993-2012: Scientometric analysis. J Pain Res 2014; 7:199-210.

5. Poleshuck EL, Katz J, Andrus $\mathrm{CH}$, Hogan LA, Jung BF, Kulick DI, Dworkin RH. Risk factors for chronic pain following breast cancer surgery: A prospective study. J Pain 2006; 7:626-634.

6. Terkawi AS, Durieux ME, Gottschalk A, Brenin D, Tiouririne M. Effect of intravenous lidocaine on postoperative recovery of patients undergoing mastectomy: A double-blind, placebo-controlled randomized trial. Reg Anesth Pain Med 2014; 39:472-477.
7. Schnabel A, Reichl SU, Kranke P, Pogatzki-Zahn EM, Zahn PK. Efficacy and safety of paravertebral blocks in breast surgery: A meta-analysis of randomized controlled trials. $\mathrm{Br}$ J Anaesth 2010; 105:842-852.

8. Tahiri Y, Tran de QH, Bouteaud J, Xu L, Lalonde D, Luc M, Nikolis A. General anaesthesia versus thoracic paravertebral block for breast surgery: A metaanalysis. J Plast Reconstr Aesthet Surg 2011; 64:1261-1269.

9. Karmakar MK, Samy W, Li JW, Lee A, Chan WC, Chen PP, Ho AM. Thoracic paravertebral block and its effects on chronic pain and health-related quality of life after modified radical mastectomy. Reg Anesth Pain Med 2014; 
39:289-298.

10. Moher D, Liberati A, Tetzlaff J, Altman DG; PRISMA Group. Preferred reporting items for systematic reviews and metaanalyses: The PRISMA statement. PLoS Medicine 2009; 6:e1000097.

11. Equivalent Opioid Calculator, available at http://clincalc.com/Opioids/ last accessed in September 27, 2014.

12. Cochrane Handbook for Systematic Reviews of Interventions. Version 5.1.0. 2011.

13. Borenstein M, Hedges LV, Higgins J, Rothstein HR. Effect sizes based on means. In: Introduction to Meta-Analysis. John Wiley \& Sons, Ltd., Chichester, UK, 2009, pp 22-32.

14. Higgins JP, Altman DG, Gøtzsche PC Jüni P, Moher D, Oxman AD, Savovic J, Schulz KF, Weeks L, Sterne JA; Cochrane Bias Methods Group; Cochrane Statistical Methods Group. The Cochrane Collaboration's tool for assessing risk of bias in randomised trials. BM] 2011; 343:d5928.

15. DerSimonian R, Kacker R. Random-effects model for meta-analysis of clinical trials: An update. Contemp Clin Trials 2007; 28:105-114.

16. Baker WL, White CM, Cappelleri JC, Kluger J, Coleman $\mathrm{Cl}$; Health Outcomes, Policy, and Economics (HOPE) Collaborative Group. Understanding heterogeneity in meta-analysis: The role of meta-regression. Int J Clin Pract 2009; 63:1426-1434.

17. Faraone SV. Interpreting estimates of treatment effects: Implications for managed care. PT 2008; 33:700-711.

18. Cochran WG. The combination of estimates from different experiments. Biometrics 1954; 101-129.

19. Julian P T Higgins SGT, Deeks JJ, Altman DG. Measuring inconsistency in metaanalyses. BM] 2003; 327:557-560.

20. Viechtbauer W. Conducting meta-analyses in R with the metafor package. Journal of Statistical Software 2010; 26:36.

21. Hannah R. Rothstein AJS, Borenstein M Publication Bias in Meta-analysis: Preven tion, Assessment, and Adjustments. WILEY, 2005.

22. Egger M, Davey Smith G, Schneider M, Minder C. Bias in meta-analysis detected by a simple, graphical test. BMJ 1997; 315:629-634.

23. Sutton AJ. Publication bias. In: Cooper LVH, Valentine JC (eds). Handbook of Research Synthesis and Meta Analysis. Russell Sage Foundation, New York, 2009, pp 435-452.

24. Wu J, Buggy D, Fleischmann E, ParraSanchez I, Treschan T, Kurz A, Mascha EJ, Sessler DI. Thoracic paravertebral regional anesthesia improves analgesia after breast cancer surgery: A randomized controlled multicentre clinical trial. Can J Anaesth 2015; 62:241-251.

25. Pusch F, Freitag $\mathrm{H}$, Weinstabl C, Obwegeser R, Huber E, Wildling E. Singleinjection paravertebral block compared to general anaesthesia in breast surgery. Acta Anaesthesiol Scand 1999; 43:770-774.

26. Klein SM, Bergh A, Steele SM, Georgiade GS, Greengrass RA. Thoracic paravertebral block for breast surgery. Anesth Analg 2000; 90:1402-1405.

27. Terheggen MA, Wille F, Borel Rinkes $\mathrm{IH}$, lonescu TI, Knape JT. Paravertebral blockade for minor breast surgery. Anesth Analg 2002; 94:355-359.

28. Naja MZ, Ziade MF, Lonnqvist PA. Nerve-stimulator guided paravertebral blockade vs. general anaesthesia for breast surgery: A prospective randomized trial. Eur J Anaesthesiol 2003; 20:897-903.

29. Kairaluoma PM, Bachmann MS, Korpinen AK, Rosenberg PH, Pere PJ. Single-injection paravertebral block before general anesthesia enhances analgesia after breast cancer surgery with and without associated lymph node biopsy. Anesth Analg 2004; 99:1837-1843.

30. Buggy DJ, Kerin MJ. Paravertebral analgesia with levobupivacaine increases postoperative flap tissue oxygen tension after immediate latissimus dorsi breast reconstruction compared with intravenous opioid analgesia. Anesthesiology 2004; 100:375-380.

31. Burlacu CL, Frizelle HP, Moriarty DC, Buggy DJ. Fentanyl and clonidine as adjunctive analgesics with levobupivacaine in paravertebral analgesia for breast surgery. Anaesthesia 2006; 61:932-937.

32. Kairaluoma PM, Bachmann MS, Rosenberg PH, Pere PJ. Preincisional paravertebral block reduces the prevalence of chronic pain after breast surgery. Anesth Analg 2006; 103:703-708.

33. Iohom G, Abdalla H, O'Brien J, Szarvas S, Larney V, Buckley E, Butler M, Shorten GD. The associations between severity of early postoperative pain, chronic postsurgical pain and plasma concentration of stable nitric oxide products after breast surgery. Anesth Analg 2006; 103:995-1000.

34. Shkol'nik LD, Vasil'ev V, Soboleva LV. [Multi-injection thoracic paravertebral anesthesia during breast cancer operations]. Anesteziol Reanimatol 2006; 4:80-85.

35. Dabbagh A, Elyasi $H$. The role of paravertebral block in decreasing postoperative pain in elective breast surgeries. Med Sci Monit 2007; 13: Cr464-467.

36. Moller JF, Nikolajsen L, Rodt SA, Ronning $\mathrm{H}$, Carlsson PS. Thoracic paravertebral block for breast cancer surgery: A randomized double-blind study. Anesth Analg 2007; 105:1848-1851.

37. Boughey JC, Goravanchi F, Parris RN, Kee SS, Kowalski AM, Frenzel JC, Bedrosian I, Meric-Bernstam F, Hunt KK, Ames FC, Kuerer HM, Lucci A. Prospective randomized trial of paravertebral block for patients undergoing breast cancer surgery. Am J Surg 2009; 198:720-725.

38. Arunakul P, Ruksa A. General anesthesia with thoracic paravertebral block for modified radical mastectomy. Chotmaihet Thangphaet [Journal of the Medical Association of Thailand] 2010; 93:S149-S153.

39. Buckenmaier CC, 3rd, Kwon KH, Howard RS, McKnight GM, Shriver $C D$, Fritz WT, Garguilo GA, Joltes KH, Stojadinovic A. Double-blinded, placebocontrolled, prospective randomized trial evaluating the efficacy of paravertebral block with and without continuous paravertebral block analgesia in outpatient breast cancer surgery. Pain Med 2010; 11:790-799.

40. Jehan M, Abdel-halim K. Continuous thoracic paravertebral block: An adjunct to general anaesthesia in major breast surgery. Egyptian Journal of Anaesthesia 2011; 27:83-87.

41. Li NL, Yu BL, Tseng SC, Hsu CC, Lai WJ, Hsieh PF, Peng WL, Chen CM. The effect on improvement of recovery and pain scores of paravertebral block immediately before breast surgery. Acta Anaesthesiol Taiwan 2011; 49:91-95.

42. Ibarra MM, GC SC, Vicente GU, Cuartero del Pozo A, Lopez Rincon R, Fajardo del Castillo MJ. [Chronic postoperative pain after general anesthesia with or without a single-dose preincisional paravertebral nerve block in radical breast cancer surgery]. Revista Espanola de Anestesiologia y Reanimacion 2011; 58:290-294.

43. Bhuvaneswari V, Wig J, Mathew PJ, Singh G. Post-operative pain and analgesic requirements after paravertebral block for mastectomy: A randomized controlled trial of different concentra- 
tions of bupivacaine and fentanyl. Indian J Anaesth 2012; 56;34-39.

44. Das S, Bhattacharya P, Mandal MC, Mukhopadhyay S, Basu SR, Mandol BK. Multiple-injection thoracic paravertebral block as an alternative to general anaesthesia for elective breast surgeries: A randomised controlled trial. Indian J Anaesth 2012; 56:27-33.

45. Abdallah FW, Morgan PJ, Cil T, McNaught A, Escallon JM, Semple JL, Wu W, Chan VW. Ultrasound-guided multilevel paravertebral blocks and total intravenous anesthesia improve the quality of recovery after ambulatory breast tumor resection. Anesthesiology 2014; 120:703-713.

46. Ilfeld BM, Madison SJ, Suresh PJ, Sandhu NS, Kormylo NJ, Malhotra N, Loland VJ, Wallace MS, Proudfoot JA, Morgan AC, Wen CH, Wallace AM. Treatment of postmastectomy pain with ambulatory continuous paravertebral nerve blocks: A randomized, triple-masked, placebocontrolled study. Reg Anesth Pain Med 2014; 39:89-96.

47. Eason MJ, Wyatt R. Paravertebral thoracic block-a reappraisal. Anaesthesia 1979; 34:638-642.

48. Capogna G, Celleno D, Fusco P, Lyons $G$, Columb M. Relative potencies of bupivacaine and ropivacaine for analgesia in labour. Br J Anaesth 1999; 82:371-373.

49. Coveney E, Weltz CR, Greengrass R, Iglehart JD, Leight GS, Steele SM, Lyerly HK. Use of paravertebral block anesthesia in the surgical management of breast cancer: Experience in 156 cases. Ann Surg 1998; 227:496-501.

50. Najarian MM, Johnson JM, Landercasper J, Havlik P, Lambert PJ, McCarthy D. Paravertebral block: An alternative to general anesthesia in breast cancer surgery. Am Surg 2003; 69:213-218; discus- sion 218.

51. Coopey SB, Specht MC, Warren L, Smith BL, Winograd JM, Fleischmann K. Use of preoperative paravertebral block decreases length of stay in patients undergoing mastectomy plus immediate reconstruction. Ann Surg Oncol 2013; 20:1282-1286.

52. Fahy AS, Jakub JW, Dy BM, Eldin NS, Harmsen S, Sviggum H, Boughey JC. Paravertebral blocks in patients undergoing mastectomy with or without immediate reconstruction provides improved pain control and decreased postoperative nausea and vomiting. Ann Surg Oncol 2014; 21:3284-3289.

53. Hura G, Knapik P, Misiolek H, Krakus A, Karpe J. Sensory blockade after thoracic paravertebral injection of ropivacaine or bupivacaine. Eur ] Anaesthesiol 2006; 23:658-664.

54. Cooter RD, Rudkin GE, Gardiner SE. Day case breast augmentation under paravertebral blockade: A prospective study of 100 consecutive patients. Aesthetic Plast Surg 2007; 31:666-673.

55. Sopena-Zubiria LA, Fernandez-Mere LA, Munoz Gonzalez F, Valdes Arias C. [Multiple-injection thoracic paravertebral block for reconstructive breast surgery]. Revista Espanola de Anestesiologia y Reanimacion 2010; 57:357-363.

56. Hara K, Sakura S, Nomura T, Saito Y. Ultrasound guided thoracic paravertebral block in breast surgery. Anaesthesia 2009; 64:223-225.

57. Boughey JC, Goravanchi F, Parris RN, Kee SS, Frenzel JC, Hunt KK, Ames FC, Kuerer HM, Lucci A. Improved postoperative pain control using thoracic paravertebral block for breast operations. Breast ] 2009; 15:483-488.

58. Curatolo M, Petersen-Felix S, Scar- amozzino P, Zbinden AM. Epidural fentanyl, adrenaline and clonidine as adjuvants to local anaesthetics for surgical analgesia: Meta-analyses of analgesia and side-effects. Acta Anaesthesiol Scand 1998; 42:910-920.

59. McClain DA, Hug CC, Jr. Intravenous fentanyl kinetics. Clin Pharmacol Ther 1980; 28:106-114.

6o. Karmakar MK. Thoracic paravertebral block. Anesthesiology 2001; 95:771-780.

61. Naja ZM, El-Rajab M, Al-Tannir MA, Ziade FM, Tayara K, Younes F, Lönnqvist PA. Thoracic paravertebral block: Influence of the number of injections. Reg Anesth Pain Med 2006; 31:196-201.

62. Luyet $C$, Siegenthaler A, Szucs-Farkas Z, Hummel G, Eichenberger U, Vogt A. The location of paravertebral catheters placed using the landmark technique. Anaesthesia 2012; 67:1321-1326.

63. Terkawi AS, Sharma S, Durieux ME, Thammishetti S, Brenin D, Tiouririne $M$. Perioperative lidocaine infusion reduces the incidence of post-mastectomy chronic pain: A double-blind, placebocontrolled randomized trial. Pain Physician 2015; 18:E139-E146.

64. Bruce J, Thornton AJ, Powell R, Johnston M, Wells M, Heys SD, Thompson AM, Cairns Smith W, Chambers WA, Scott NW; Recovery Study Group. Psychological, surgical, and sociodemographic predictors of pain outcomes after breast cancer surgery: A population-based cohort study. Pain 2014; 155:232-243.

65. Terkawi AS, Karakitsos D, Elbarbary M, Blaivas M, Durieux ME. Ultrasound for the anesthesiologists: Present and future. Scientific World Journal 2013; 2013:683685. 